\title{
Effects of the internal structures of monolith ceramic substrates on thermal and hydraulic properties: additive manufacturing, numerical modelling and experimental testing
}

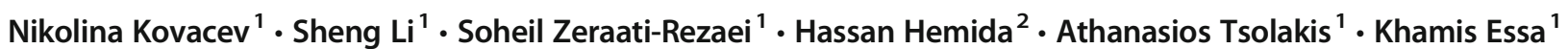

Received: 21 August 2020 / Accepted: 9 December 2020 / Published online: 28 December 2020

(C) The Author(s) 2020

\begin{abstract}
Rigorous emission regulations call for more efficient passive control catalysts for exhaust gas aftertreatment without affecting the internal combustion process and $\mathrm{CO}_{2}$ emissions. Although the state-of-art ceramic honeycomb substrate designs provide high surface area and a degree of flexibility for heat and mass transfer adaptations, additional emission reduction benefits can be achieved when more flexible designs to provide effective thermal management are introduced. The conventional cordierite honeycomb substrates are manufactured by extrusion; therefore, only substrates with straight channels can be fabricated. This study aims to highlight any design limitations of conventional substrates by employing additive manufacturing as the main method of manufacturing diamond lattice structures using DLP (digital light processing) technology. Both conventional substrates and diamond lattice structures are studied numerically and experimentally for flow through resistance and temperature distribution. Numerical predictions and experimental results showed good agreement. The results show the increase of the axial temperature distribution for diamond lattice structures and a significant decrease of the pressure drop (38-45\%) in comparison with the benchmark honeycomb with similar surface area.
\end{abstract}

Keywords Additive manufacturing $\cdot$ Monolith $\cdot$ Ceramic substrate $\cdot$ CFD $\cdot$ Honeycomb

\section{Nomenclature}

A Cross-sectional area of the substrate, $\mathrm{m}^{2}$

AM Additive manufacturing

CPSI Cells per square inch

D Diameter of the substrate, $\mathrm{mm}$

$d_{\mathrm{p}} \quad$ Lattice pore diameter, $\mathrm{mm}$

$d_{\mathrm{h}} \quad$ Hydraulic diameter of the honeycomb channel, mm

$d_{\mathrm{s}} \quad$ Lattice strut diameter, $\mathrm{mm}$

GHSV Gas hourly space velocity through the substrate, ratio between the gas volume flow rate and the substrate volume, $\mathrm{h}^{-1}$

Nikolina Kovacev

nxk889@student.bham.ac.uk

1 School of Mechanical Engineering, University of Birmingham, Edgbaston B15 2TT, UK

2 School of Civil Engineering, University of Birmingham, Edgbaston B15 2TT, UK
GSA Geometric surface area, $\mathrm{m}^{2}$

$H \quad$ Heat transfer coefficient, W/ $/ \mathrm{m}^{2} \mathrm{~K}$

HC Conventional honeycomb substrate

$k_{\mathrm{S}} \quad$ Solid thermal conductivity, W/mK

$L \quad$ Length of the entire substrate, $\mathrm{mm}$

$L_{\mathrm{c}} \quad$ Cell length, $\mathrm{mm}$

$L_{\mathrm{s}} \quad$ Strut length, $\mathrm{mm}$

$\dot{m} \quad$ Mass flow rate, $\mathrm{kg} / \mathrm{h}$

OFA Open frontal area

$\triangle P \quad$ Pressure drop through the substrate, $\mathrm{Pa}$

$Q \quad$ Total heat loss, W

Re Reynolds number based on strut diameter

$S_{\mathrm{v}} \quad$ Specific surface area, $\mathrm{m}^{-1}$

$T_{\text {gas, in }}$ Temperature of the gas at the inlet of the substrate, $\mathrm{K}$

$T_{\text {gas,out }}$ Temperature of the gas at the outlet of the substrate, $\mathrm{K}$

$T_{\text {wall,ave }}$ Average temperature of the outer walls of the substrate, $\mathrm{K}$

$V_{\text {bcc }} \quad$ Volume of the solid substrate, $\mathrm{m}^{3}$

$V_{\text {cylinder }}$ Volume of the entire cylinder substrate, $\mathrm{m}^{3}$

$\varepsilon \quad$ Porosity of the substrate 
$\Phi \quad$ Specific length ratio, the ratio of pore diameter and strut thickness

\section{Introduction}

Environmental concern and ever-changing emission regulations have raised the significance of improving the performance of the exhaust gas aftertreatment system for stationary and mobile applications [1, 2]. In the 1970s, initial trials of exhaust gas purification incorporated placing a catalytic converter in all petrol vehicles [3]. The key part of the converter, honeycomb monolith, typically manufactured by extrusion, consists of thousands of straight, parallel, flow-through channels coated with noble metals accountable for catalytic reactions [4-6]. Due to the restrictions of the extrusion process, the channel design is of a simple shape with thin walls separating the individual channels $[7,8]$. Only limited geometric shapes of the channels can be manufactured, such as square, hexagonal or triangular $[9,10]$. Research shows that hexagonal and square channels show similar performance and pressure drop under the same experimenting conditions. Contrarily, triangular channels show the poorest performance [11]. Hotspots and non-isothermal temperature profiles in axial and radial directions present additional issues associated with the substrate design $[12,13]$. The laminar flow inside of the honeycomb channels decreases the heat and mass transfer [14]. The awareness of the inefficient use of the catalyst full volume led to research of new possible designs of the substrate following the improvement of the manufacturing opportunities.

One way of achieving the necessary requirements to increase the catalyst performance is to cautiously direct the parameters of the substrate structure to achieve the desired pressure drop and improved heat transfer. An interesting approach to enhanced monolith designs is non-stochastic structures that include 3D lattice structures of strut-and-node arrangement and custom unit cells. Non-stochastic lattice structures consist of unit cells periodically arranged in all three dimensions with the most common octet, cube, hexagon and tetrakaidekahedron, all inspired by foam designs $[14,15]$. Topology-optimized lattice structures have been utilized in automotive industry for weight reduction and improvement of the strength of bulk parts [16]. For catalytic applications, modified regular structures manufactured by robocasting provided improved mass transfer compared with the honeycomb sample, with a fairly higher pressure drop [17]. The tortuous path in the channels upsurges the transport between the catalyst surface and the bulk of reactant and product $[18,19]$. Recent research has revealed rotated cubic cells as a replacement for honeycombs [14]. Samples with $3 \mathrm{~mm}$ and $4 \mathrm{~mm}$ cell size and strut thickness of $0.5 \mathrm{~mm}$ were manufactured and experimentally tested $[14,15]$. Due to the manufacturing limitations, the samples had a low specific surface area which proved to be a disadvantage [14].
Numerical simulations can give detailed insights into specifics that are not possible or are difficult to capture throughout experimental trials to aid the design of the new catalytic supports. The simplest modelling method for honeycombs is a single-channel method, where all channels are assumed to behave alike; however, this assumption is not correct. The flow maldistribution and heat losses to the surroundings are discarded in the single-channel models [10, 20-23]. Multichannel models, such as the subgrid-scale model with a couple of representative channels, have the same drawbacks as the single-channel method [24]. Continuum models, where the pressure drop of the monolith is implemented into the model from calculations, need to have assigned a correct heat flux at boundary $[22,25]$. The thermal conditions, in reality, cannot be set as isothermal due to the temperature variations along the length and cross-section of the monolith. Likewise, numerical simulations have been utilized, to some extent, to study the fluid dynamics and heat transfer properties of foams and nonstochastic lattice structures. A comprehensive analysis of pressure drops in virtually reconstructed open cell foams, combining numerical and experimental studies, showed the open-cell foams outperform honeycomb monoliths in the range of low Reynolds numbers [26]. Alternatively, foams can be reconstructed by Laguerre-Voronoi tessellations, with the main drawback being the increase of the computational load [27]. Previous studies have indicated that foam-based catalysts demonstrate greater performance in comparison with the honeycomb in terms of conversion, but might exhibit higher pressure drops $[3,26,28]$. While foams seem to show increased performance, their non-controllable structure makes it challenging to foresee the flow behaviour [15]. To simplify the modelling of the foams in the past, the foam structure had been represented with regular cells, such as Kelvin cells. The regular structures have actually proved to have a superior trade-off between the mass transfer and pressure drop [29]. Moreover, their superior properties led to study the regular structures as potential catalyst substrates [14, 30]. Modelling of complex non-stochastic structures is particularly challenging; thus, short domains consisting of only a couple of cells in the flow direction are generally used for numerical simulations [30-32]. However, the short domains could affect the simulation results as the flow might not be fully developed [31].

Advanced manufacturing technologies (AMT) are progressively used in many different industries. Precise and complex components can be fabricated by machining processes such as ball end milling [33] and turning [34]. Furthermore, laser hardening offers short processing time and higher performance for 3D complex shapes [35]. Additive manufacturing eases the manufacturing of complex geometrical shapes by layer by layer addition of material. The improvements in the AM technologies have allowed direct fabrications of lattice structures. Selective laser melting (SLM) is a widely employed additive 
manufacturing process that can be used for printing of intricate three-dimensional (3D) structures for various applications [30-32]. Ti-6Al-4V alloy-based 3D meshes with diamond unit cells were manufactured with concept laser M2 for optical applications [36]. Moreover, the same technology was utilized to manufacture Ti-6Al-4V optical lattice mesh structure that can be used as an oil sensor [37]. In addition, the studies on the effect of SLM process parameters and their optimization were performed for manufacturing of biomedical implants [38]. Additive manufacturing of ceramic materials has been an ongoing topic of research due to their challenging processing requirements [39]. One of the challenges is the reduced cure depth in ceramic suspensions due to scattering, resulting in a decrease of the bonding between the layers. However, reducing the layer thickness to increase the bonding of the layers as a consequence increases the building time. Correspondingly, the viscosity of the suspension must be optimised to ensure uniform layer recoating during the build [40]. Nevertheless, AM can overcome the traditional ceramic manufacturing methods limitations, such as complex geometry production. Net shape $\mathrm{YSZ} / \mathrm{Al}_{2} \mathrm{O}_{3}$ nanocomposite micro-components were successfully manufactured through a process based on soft lithography and powder dispersion [41]. Techniques involving polymerization of the photoactive resin can generally be divided into stereolithography (SLA) based on spot scanning and digital light processing (DLP) based on mask-image-projection [42]. Lattice structures have been manufactured by stereolithography in the past; however, the disadvantages of this process include the need of support for manufacturing and the stair-case effect which can be highly detrimental under load [15, 43]. Digital light processing AM technology generally has faster manufacturing speed and is advantageous for building small components [42]. Thus, digital light processing (DLP) additive manufacturing technology has been used in this study due to the significant advantages of high precision and low cost for advanced ceramic manufacturing [41].

Research conducted so far on the improvement of the monolith designs has merely explored unit cells derived from foams, such as Kelvin cell or a simple cubic cell $[14,17]$. The dimensional limitations of the manufacturing technique used to manufacture the substrates cause the aforementioned to have large strut diameters and inadequate substrate dimensions resulting in low geometrical surface areas [14]. Short domains chosen for the experiments and numerical modelling of lattice structures can cause inaccuracies in pressure drop prediction and overall performance as the flow might not be fully developed [14, 31]. Morphological parameters of honeycomb and lattice design need to be investigated in conditions other than isothermal. In this study, hot gas is used as the heat source rather than isothermal conditions on the outside wall. The numerical model contains longer length of the lattice structure with a higher aspect ratio. The effect of geometrical structure between lattice and traditional monolith substrate in terms of heat transfer and flow resistance is investigated by employing a steady-state three-dimensional conjugate heat transfer model. The aim of this paper is to develop and manufacture a lattice monolithic ceramic substrate. Computational fluid dynamic model is developed to aid the design and is validated for both designs and used to compare between them. The performance of the two substrate designs is tested in terms of temperature profile and pressure drop in a non-reactive environment. Finally, the effect of lattice design on the specific surface area, pressure drop and thermal management is investigated.

\section{Methodology}

\subsection{Design of lattice structures}

Lattice can be defined as a structure which consists of a regular network of struts connected by nodes in a threedimensional space. The unit cell size, type, strut size and cell orientation have a considerable influence on the surface area, thermal properties of the structure and fluid flow behaviour. Diamond lattice cell has been selected as the representative model as it has shown great performance for other applications and it is self-supportive, which is of great importance for successful additive manufacturing [37, 44]. The CAD model of the investigated diamond lattice substrate is shown in Fig. $1 \mathrm{a}$, with the corresponding internal structure in Fig. $1 \mathrm{~b}$ and a diamond unit cell in Fig. 1c and d, illustrating the main properties of the diamond lattice structure. The porosity was calculated from the volume distribution of the solid and total volume of the cylindrical samples as shown in Eq. 1.

$\varepsilon=\left(1-\frac{V_{\mathrm{BCC}}}{V_{\text {cylinder }}}\right)$

The specific surface area was calculated as the geometrical surface area of the whole substrate divided by the volume of the cylinder as shown in Eq. 2.

$S_{\mathrm{v}}=\frac{\mathrm{GSA}}{V_{\text {cylinder }}}$

Honeycomb monoliths are available in different cell density and shapes. Nevertheless, the most common commercial honeycomb is a square channelled 400 CPSI $[14,26,45$, 46]. Therefore, a square channelled honeycomb monolith with 400 CPSI and $0.2 \mathrm{~mm}$ thick walls is used as the benchmark. The CAD model of the honeycomb substrate is illustrated in Fig. 2a. Figure 2b represents the internal structure and Fig. $2 \mathrm{c}$ single channel. The main properties of the honeycomb are channel diameter of $1.05 \mathrm{~mm}$, porosity of 0.68 and specific surface area of $2480 \mathrm{~m}^{-1}$. 

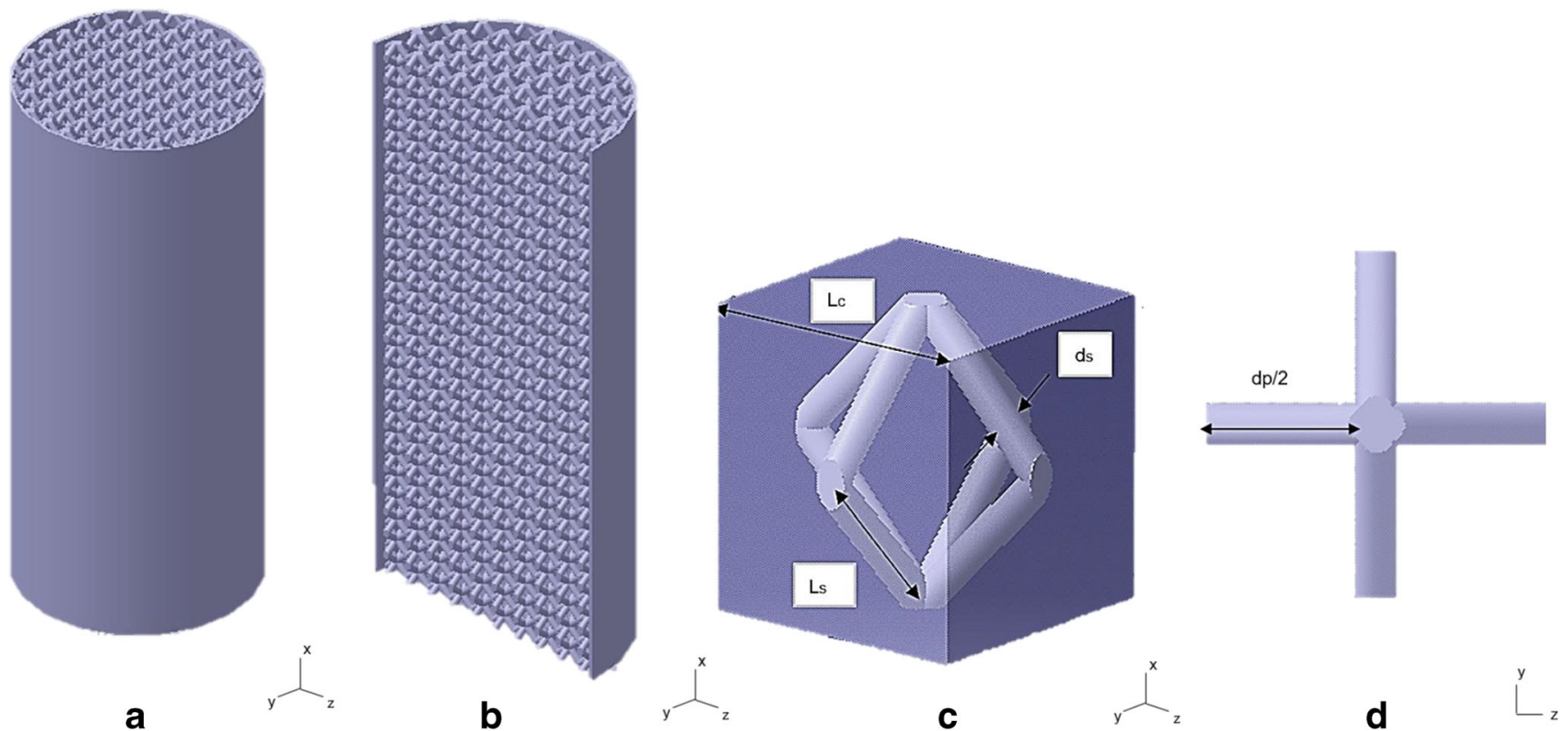

Fig. 1 CAD representation of a full-length lattice model; $\mathbf{b}$ internal structure of the lattice model; $\mathbf{c}$ unit cell diamond lattice with geometrical parameters, $L_{\mathrm{s}}$ strut length, $L_{\mathrm{c}}$ cell length, $d_{\mathrm{s}}$ strut diameter; $\mathbf{d}$ unit cell in flow direction, where $d_{\mathrm{p}} / 2$-half pore diameter

\subsection{Numerical modelling}

In order to aid the design of the lattice structures, a numerical approach using computational fluid dynamics (CFD) is used to predict the effect of the internal structure of the substrate on fluid dynamics, pressure drop and temperature distribution. The main focus of the numerical study is on the physical behaviour of the flow within the substrate; therefore, the chemical reactions are not taken into the account for simplification and to place the interest strictly on the flow behaviour driven by the geometry change, which is a common practice when investigating fluid flow in substrates [1, 30, 47]. The main idea is that, with the lattice design, the temperature distribution in radial and axial direction of the substrate will be considerably different than of the traditional honeycomb substrate, concluding that the geometry can influence the temperature distribution. A finite-volume-based commercial code ANSYS CFX enables to solve the conjugate heat transfer problems with two separate domains, where the thermal energy of solid and fluid is exchanged in their interface [48]. The equations required are momentum balances and energy balances for the solid and fluid phases. The transport of enthalpy through the

Fig. 2 CAD model of a fulllength honeycomb model, $\mathbf{b}$ internal honeycomb structure, and $\mathbf{c}$ single channel
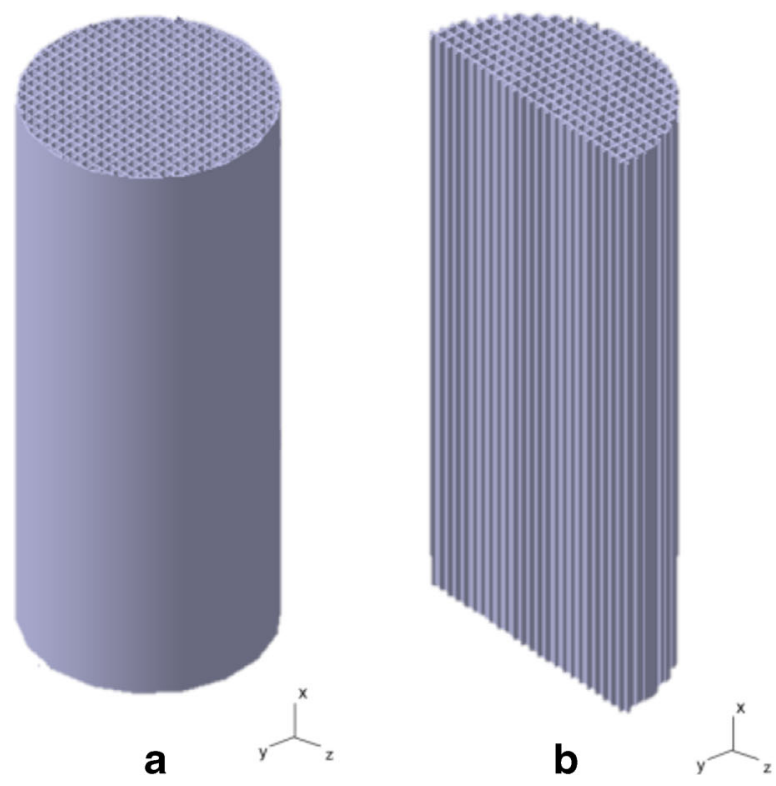

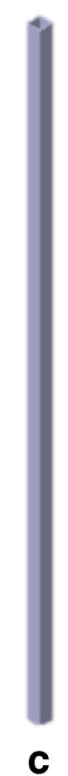


fluid and heat transfer is modelled with thermal energy model. Steady-state Navier-Stokes equations were solved in the laminar model for honeycomb substrate and in shear stress transport (SST) $\mathrm{k}-\mathrm{\omega}$ model for the lattice substrate. It is important to note that two CFD models have been developed and validated; one for the lattice structure and one for the honeycomb (this is because the lattice structure has different dimensions due to the manufacturing limitation). Second-order upwind biased discretization is used to calculate the advection terms in the discrete finite volume equations. Residuals are the most important measure of convergence; hence, RMS residuals are set as the convergence criteria with the magnitude of limit $10^{-6}$. Pressure drop was monitored as the value of interest and it was ensured that the steady-state value was reached with the overall imbalance less than $1 \%$. The boundary conditions are constructed with mass flow rate and temperature at the inlet, zero-gauge pressure at the outlet, and constant heat transfer coefficient at the walls. The computational domain is represented as a quarter of the full substrate with lateral boundaries as symmetry for the honeycomb and periodic for the lattice. The dimensions of the honeycomb and lattice domain are matched with the dimensions of the substrates in the experiments. The fluid domain was extended by $3 \mathrm{~mm}$ before and after the solid. The boundary conditions and the computational domains are shown in Fig. 3. Table 1 summarizes in detail the computational domains and the boundary conditions for the numerical models. Thermal conductivity of $2.5 \mathrm{~W} / \mathrm{mK}$ is used for the cordierite honeycomb in the present model $[1,49]$. Zirconia has a reported thermal conductivity in the range of $2.2-2.9 \mathrm{~W} / \mathrm{mK}$ [50]. The value chosen was the same as for the cordierite sample as in this range significant differences in the temperatures were not observed.

The fluid is considered as an ideal gas; thus, the equation of state $p V=n R T$ is valid. The temperature of the incoming exhaust gas in automotive exhaust systems can be as high as
$1173 \mathrm{~K}$ [51]. Relatively high air temperature of $923 \mathrm{~K}$ was chosen for model validation for higher experimental measurement accuracy. The heat transfer coefficient was calculated from the average sample surface temperature and inlet and outlet temperatures obtained from the experiment [52]. Radiation heat transfer was not taken into the account since the outer tube temperatures were low [53]. Total heat losses Q were obtained with Eq. 3:

$Q=\dot{m} \mathrm{c}_{\mathrm{p}, \text { air }}\left(T_{\text {gas,in }}-T_{\text {gas,out }}\right)$

Total heat transferred from the substrate wall, through the wrapping and the pipe is calculated from Eq. 4:

$Q=h A T_{\text {wall,ave }}$

Equating Eqs. 3 and 4, heat transfer coefficient can be derived as Eq. 5:

$\frac{h=\dot{m} c_{\mathrm{p}, \text { air }}\left(T_{\mathrm{gas}, \text { in }}-T_{\mathrm{gas}, \text { out }}\right)}{\pi D L T_{\text {wall,ave }}}$

The laminar flow $(R e=125-1250)$ in the honeycomb due to the very small channel diameter $(1.05 \mathrm{~mm})$ justifies the use of the laminar model. The determination of the flow behaviour in the lattice includes calculation of Reynolds number with appropriate characteristic length. Various definitions of the characteristic length for lattice structures are found in the literature. Strut diameter, mean cell diameter or hydraulic diameter can be used to find the Reynolds number [14, 31, 54]. In this study, the Reynolds number was calculated with the strut diameter as the characteristic length as suggested in [14].The Reynolds number based on the strut diameter in this study lies in the range of 2-25

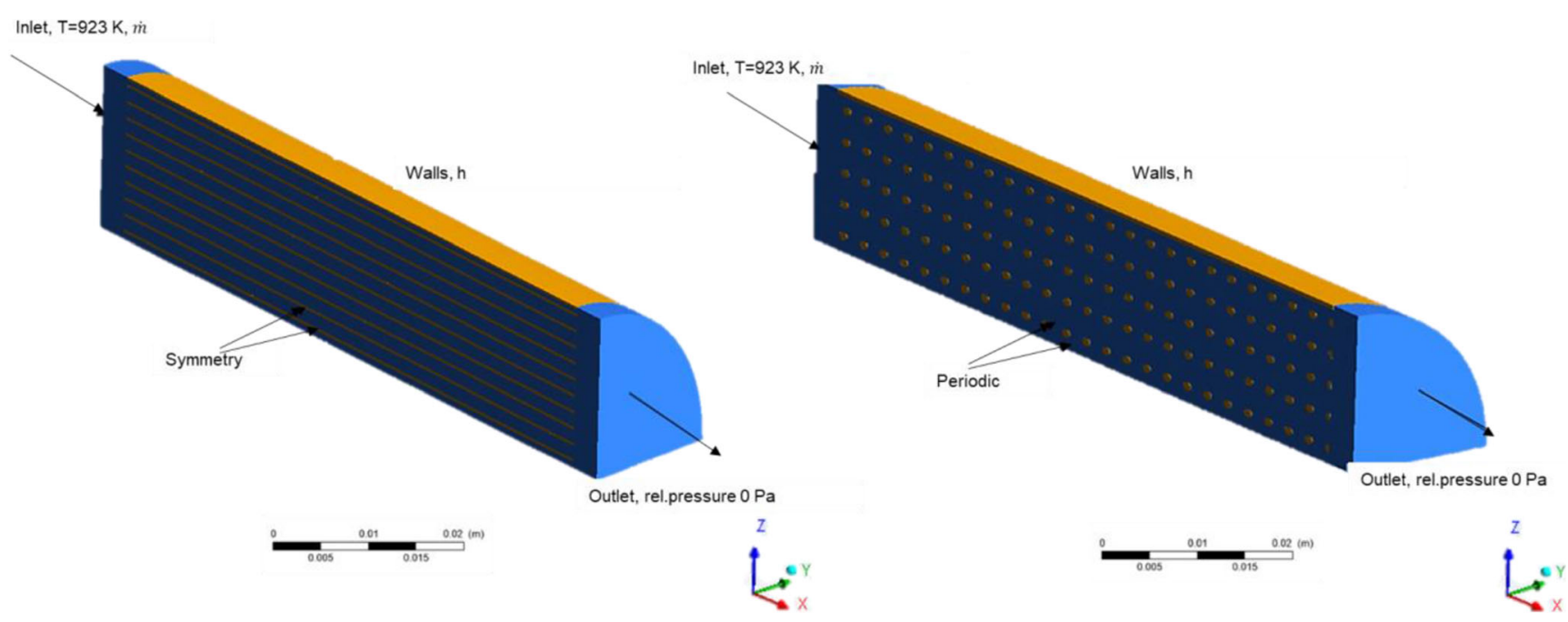

Fig. 3 Solid (yellow) and fluid (blue) domains with boundary conditions for honeycomb (left) and lattice (right) 
Table 1 Summary of the computational domains and boundary conditions

\begin{tabular}{|c|c|c|c|}
\hline Domain & Section & Dimensions: radius $\times$ length $(\mathrm{mm})$ & Condition \\
\hline Fluid domain & $\begin{array}{l}\text { Honeycomb } \\
\text { Lattice }\end{array}$ & $\begin{array}{l}12.5 \times 63 \\
12.7 \times 67\end{array}$ & $\begin{array}{l}\text { Air at } 923 \mathrm{~K} \\
k_{\mathrm{f}} \text {-Sutherland formula } \\
\rho \text {-Sutherland formula }\end{array}$ \\
\hline Solid domain & $\begin{array}{l}\text { Honeycomb } \\
\text { Lattice }\end{array}$ & $\begin{array}{l}12.5 \times 57 \\
12.7 \times 61\end{array}$ & $\begin{array}{l}\text { Cordierite, } k_{\mathrm{s}}=2.5 \mathrm{~W} / \mathrm{mK} \\
\mathrm{ZrO}_{2}, k_{\mathrm{s}}=2.5 \mathrm{~W} / \mathrm{mK}\end{array}$ \\
\hline Boundary conditions & Named section & & Condition \\
\hline Mass flow rate inlet & Inlet & & $\dot{m}=0.4-1.8 \mathrm{~kg} / \mathrm{h}$ \\
\hline Pressure outlet & Outlet & & $P_{\text {outgauge }}=0 \mathrm{~Pa}$ \\
\hline Wall with constant $\mathrm{h}$ & Wall_fluid & & No-slip, $h=16 \mathrm{~W} / \mathrm{m}^{2} \mathrm{~K}$ \\
\hline Wall with constant $\mathrm{h}$ & Wall_solid & & No-slip, $h=16 \mathrm{~W} / \mathrm{m}^{2} \mathrm{~K}$ \\
\hline Interface & Condition & & \\
\hline Fluid-solid interface & $\begin{array}{l}\text { No-slip, heat transfer, symmetry condition through } x \text {-axis (h } \\
\text { periodic condition through } x \text {-axis (lattice) }\end{array}$ & oneycomb) & \\
\hline Solid-fluid interface & $\begin{array}{l}\text { Heat transfer, symmetry condition through } x \text {-axis } \\
\text { (honeycomb) periodic condition through } \mathrm{x} \text {-axis (lattice) }\end{array}$ & & \\
\hline
\end{tabular}

suggesting laminar to early transition regime [14]. The simulations for the lattice structure were performed both by laminar and SST-k- $\omega$ model. The simulation results were compared with the experimental results, resulting in a smaller discrepancy when using SST-k- $\omega$ model. Consequently, the SST-k- $\omega$ model is selected, given that it is able to deal with transitional flows and performs well in the proximity of solid walls. The mesh is constructed using Ansys software package built-in mesher. The fluid domain of the honeycomb channels is meshed with hexahedral elements with the mesh details shown in Fig. 4 (left), whereas the inlet and outlet sections are meshed with unstructured mesh. Mesh independence is reached at element count of $8,162,045$. The solid channels of the monolith substrate are meshed using adaptive hexahedral mesh with a global size of $0.2 \mathrm{~mm}$. It is assumed that there are no considerable thermal gradients across the structure due to very fine thickness of the channel walls, which is confirmed through a set of additional simulations with only $0.3 \%$ error between temperatures at the interface when using mesh with 350,373 (element size $0.2 \mathrm{~mm}$ ) and 6,849,920 elements (element size $0.04 \mathrm{~mm}$ ). For the lattice structure, different meshing approach is used. Owing to the complex structure, unstructured mesh is generated for both solid and fluid domain. The details of the mesh for the fluid domain are presented in Fig. 4 (right). Curvature-based mesh refinement with fine mesh around the lattice strut surface is used, with mesh size gradually increasing away from the surface at growth rate of 1.3 until the maximum value. The mesh independent solution is reached with
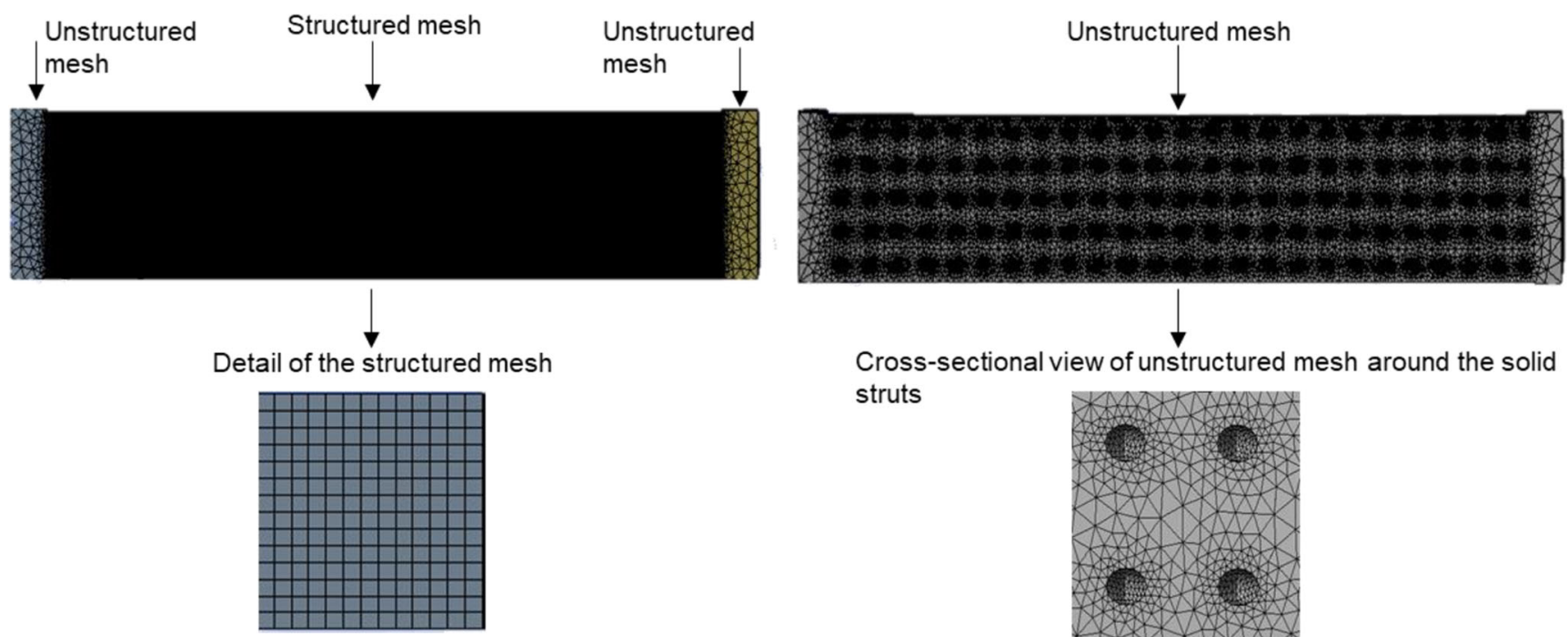

Fig. 4 Example of the CFD mesh used in the present work. Honeycomb mesh with channel mesh detail (left), unstructured mesh of the lattice substrate with cross-sectional view of the mesh detail (right) 
$7,912,022$ elements. Solid domain is meshed with adaptive unstructured mesh with a global size of $0.2 \mathrm{~mm}$. The main parameter for the mesh dependence test is pressure drop, as higher variations of calculated pressure gradients are noticed with change of the element count, whereas the temperature values only varied slightly. Figure 5 represents the variation of pressure drop values with the number of elements for the honeycomb and lattice model. The highest RMSE \% from the experimentally obtained pressure drop is less than $10 \%$ for both structures using mesh with around 8 million elements for the fluid domains.

\subsection{Additive manufacturing}

Stereolithography-based method with DLP light source is used to polymerize the photocurable resin and form the green bodies in this study. The aforementioned is a promising additive manufacturing technology for complex shape ceramic part production [42]. The DLP technology might overcome the manufacturing limitations observed in previous research, where the resulting substrates had low specific surface area, requiring higher overall catalyst volume [14]. The samples were manufactured on Admaflex 130 (Admatec Europe BV, The Netherlands) with a x,y resolution of $40 \mu \mathrm{m}$. The printing area consists of a transparent glass surface at the bottom and the building platform, which moves vertically up and down, at the top. The light source with DMD chip comprising an array of several thousand microscopic mirrors that rotate according to the pixels in the image is located under the glass. The Admaflex 130 is equipped with a rotating foil system which transports the slurry on the foil from the reservoir to the manufacturing zone and to the pump where the excess slurry is pumped back to the reservoir. Photopolymerisable light sensitive resin is exposed to the light $(405 \mathrm{~nm})$, which subsequently cures and hardens the resin. The process of curing layer by layer is repeated until the final three-dimensional green body is built [55]. The

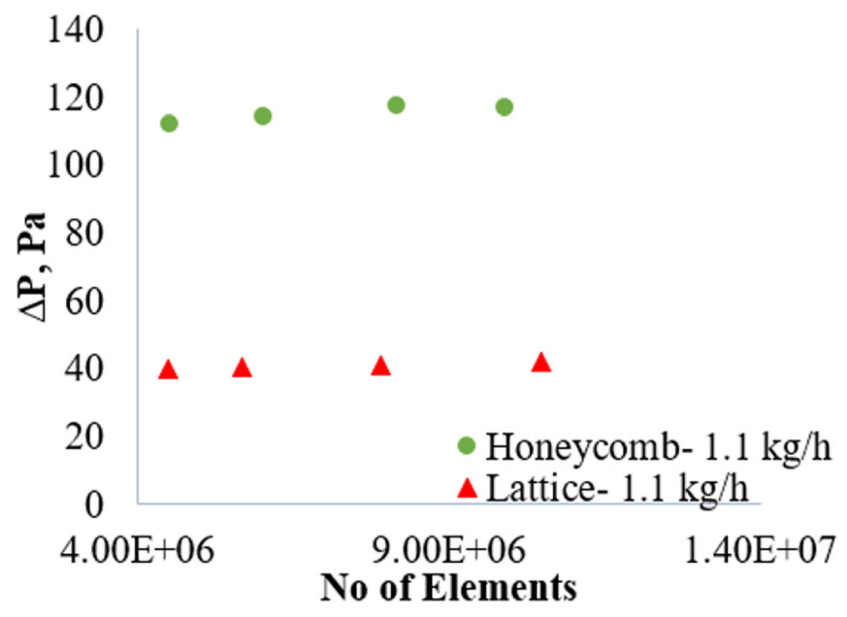

Fig. 5 Mesh independence study for honeycomb and lattice model commercial ceramic suspension (Z-130, Admatec Europe BV, The Netherlands) was used for manufacturing of the representative diamond lattice sample. The Z-130 feedstock contains a mixture of photosensitive resins and a solid loading of zirconia powder. The layer thickness was set as $25 \mu \mathrm{m}$ and the exposure time was varied between 1.5 and $2 \mathrm{~s}$. The remaining slurry on the surface of the sample was cleaned by immersing the sample in ultrasonic bath filled with ethanol. Two consequent thermal treatments were performed to achieve a dense ceramic substrate. The debinding in a tube furnace (TSH/1S/75/450, Elite Thermal Systems Ltd, UK) and sintering in a chamber furnace (HTF 17/27, Carbolite Gero, UK) were performed using cycles recommended by the Admatec company. The final sintered product is shown in Fig. 6a, with a diameter of $25.4 \mathrm{~mm}$ and $61.3 \mathrm{~mm}$ length achieved by carefully attaching four shorter substrates with Zirconia Resbond 904 adhesive (Final Advanced Materials, France). The manufactured sample has a pore diameter of $1.85 \mathrm{~mm}$, strut diameter $0.65 \mathrm{~mm}$, specific surface area of $1480 \mathrm{~m}^{-1}$, and the porosity of 0.73 . The strut thickness was measured on the realized sample with Digital Vernier Caliper (150 mm Digital Caliper, RS PRO, UK) and confirmed with SEM (JCM-6000, JEOL Ltd., Japan) as reflected in Fig. 6b; similar approach was used by [14, 56]. The benchmark cordierite honeycomb used for the experimental validation has square channels with a cell diameter of 1.05 $\mathrm{mm}$, separated by $0.2 \mathrm{~mm}$ walls. The diameter of the sample is $25 \mathrm{~mm}$ and the length is $57 \mathrm{~mm}$. The geometric specific surface area of the sample is $2870 \mathrm{~m}^{-1}$ with the porosity of 0.68 .

\subsection{Experimental setup}

A bespoke test facility was designed and constructed to allow for heat transfer characterization and pressure drop measurements of both the conventional honeycomb support and the novel additive manufactured lattice support. The main functions of the test facility are to measure the inlet and outlet air temperature, surface temperature of the substrate, and lastly to measure the pressure drop over the substrate.

The schematic of the experimental setup is shown on Fig. 7a. Compressed air is fed into variable flow meter (Omega, FL-2517, accuracy: $\pm 5 \%$ of full-scale reading, Omega Engineering, UK) with a valve used to control the flow rate. The air flow is led through a heated line and stainless steel spiral placed in the furnace to heat the air to a high temperature. The sample is wrapped with insulation mat and placed into the testing section. Once the air before the substrate ( $T_{\text {gas, }}$ in) reaches $923 \mathrm{~K}$ and the values of interest do not change over time, the system is being considered in steady state and the temperatures and differential pressure values are captured. The vertical testing section shown in Fig. $7 \mathrm{~b}$ is equipped with two openings for the differential pressure sensor (NXP MPX5010DP piezoresistive transducers with 5.0\% maximum error, range 0 to $10 \mathrm{kPa}$, RS Components Ltd, UK) connection 
Fig. 6 Image of the a final AM lattice with internal diamond structure, b SEM image of one diamond cell of the sintered AM substrate with apparent AM layers

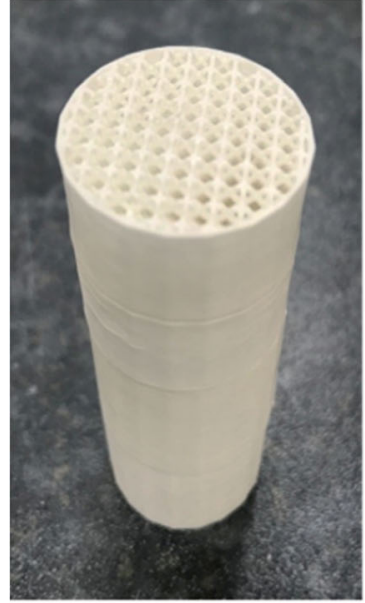

a

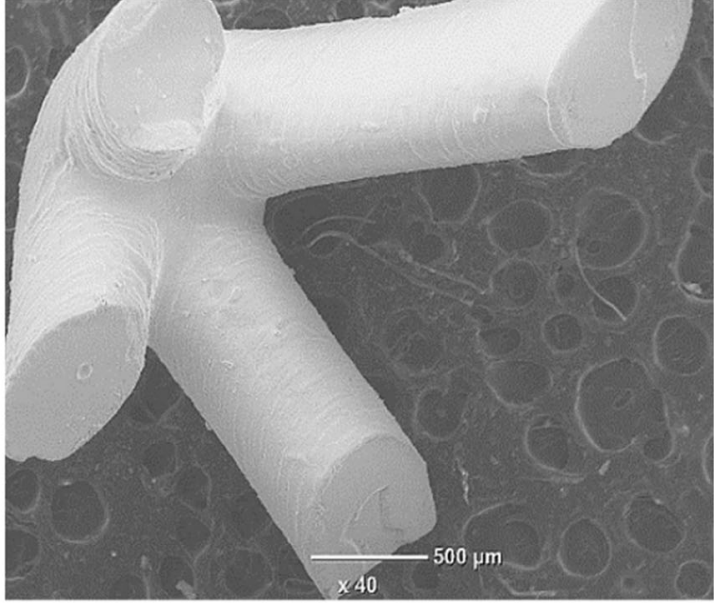

b and two openings for temperature (K type, TC direct, UK) measurements before and after the substrate sample. Temperatures across the substrate $\left(T_{1}, T_{2}, T_{3}, T_{4}, T_{5}, T_{6}\right)$ were measured to obtain the temperature distribution as depicted in Fig. 7c. The air volumetric flow rate is controlled to yield mass flow rates of $0.4 \mathrm{~kg} / \mathrm{h}, 0.7 \mathrm{~kg} / \mathrm{h}, 1.1 \mathrm{~kg} / \mathrm{h}$, and $1.8 \mathrm{~kg} / \mathrm{h}$ representing the range of gas space hourly velocities (GHSV) of approximately 30,000 to $170,000 \mathrm{~h}^{-1}$.

\section{Results and discussion}

\subsection{Model validation}

The pressure loss of substrates is highly dependent on the channel design, geometry, length, and hydraulic diameter of the channels [47]. The substrates must be designed in a way to offer high surface area for catalytic reactions, low back-pressure, and fast light-off without compromises in mechanical properties. Therefore, our aim is to understand the pressure drop and thermal behaviour of both the conventional honeycomb and diamond lattice structures. The validation of the numerical model consists of comparing the experimental results for pressure drop and temperature $\left(T_{1}, T_{2}, T_{3}, T_{4}, T_{5}, T_{6}\right)$ with the results obtained by numerical simulations. The validation has been achieved for various mass flow rates. The obtained results for the temperature distribution showed similar trends; hence, for simplification purposes, only the results for $1.1 \mathrm{~kg} / \mathrm{h}$ are presented. The lattice sample is $4 \mathrm{~mm}$ longer than the 400 CPSI honeycomb substrate due to the manufacturing limitations. However, it is believed that the minor difference in the length of the lattice will not have a great impact on the obtained results. The validation of computation fluid dynamic models for both lattice and honeycomb design is presented in this section.

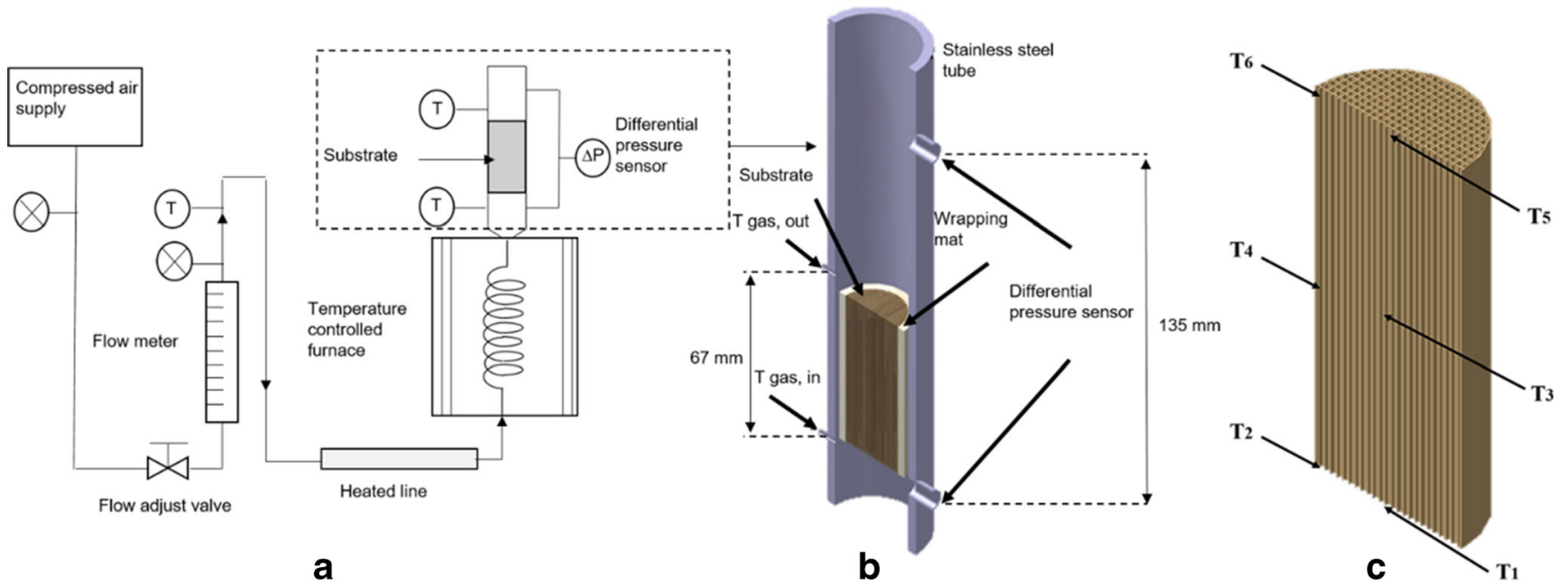

Fig. 7 a Schematic of the experimental setup. b CAD model of the cross-section of the testing section with the main segments. $\mathbf{c}$ Position of the thermocouples to measure temperature in central points $\left(T_{1}, T_{3}, T_{5}\right)$ and at the surface of the substrate $\left(T_{2}, T_{4}, T_{6}\right)$ 


\subsubsection{Validation of model for the honeycomb structure}

Figure 8 shows the experimental results of the pressure drop for honeycomb substrate with varying mass flow rate $(0.4-1.1$ $\mathrm{kg} / \mathrm{h}$ ) and constant inlet gas temperature of $923 \mathrm{~K}$. Note that the error bars are in the order of graph point size. Due to the small channel diameter $(1.05 \mathrm{~mm})$ and low Reynolds number $(<2300)$, the channels exhibit laminar flow behaviour. The model predicts the minimum pressure drop for the lowest flow rate $(0.4 \mathrm{~kg} / \mathrm{h})$ as $41 \mathrm{~Pa}$ with a linear increase of the pressure drop with the increase in the mass flow rate, resulting in pressure drop of $117 \mathrm{~Pa}$ at the highest examined flow rate $(1.1 \mathrm{~kg} /$ h). Similar trend, where the pressure drop shows a linear dependency to the mass flow rate, is found in the literature [47, 57]. It can be concluded that the CFD prediction results for pressure drop agree well with experimentally measured pressure drops.

The second part of the study is to validate the numerical model against experimental data for temperature measurements. Figure 9 shows the temperature distribution along the honeycomb substrate, at the centre $\left(T_{1}, T_{3}, T_{5}\right)$ as well as the surface $\left(T_{2}, T_{4}, T_{6}\right)$, with mass flow rate of $1.1 \mathrm{~kg} / \mathrm{h}$. Note that the error bars lie within the point. The maximum temperature equal to the inlet gas temperature of $923 \mathrm{~K}$ is found at the centre of the inlet of the honeycomb substrate. The temperature gradually decreases as the flow reaches the exit of the substrate and the lowest temperature point is located at the outer surface of the honeycomb substrate with a value of $768 \mathrm{~K}$. The temperature gradient between the centre and the surface of the monolith is expected due to the heat losses to the surroundings. The axial gradient from the inlet centre to the exit centre is around $\Delta T_{\mathrm{T} 1-\mathrm{T} 5}=82 \mathrm{~K}$ for the honeycomb substrate highlighting the non-uniform axial temperature distribution. Very good agreement between the CFD model prediction

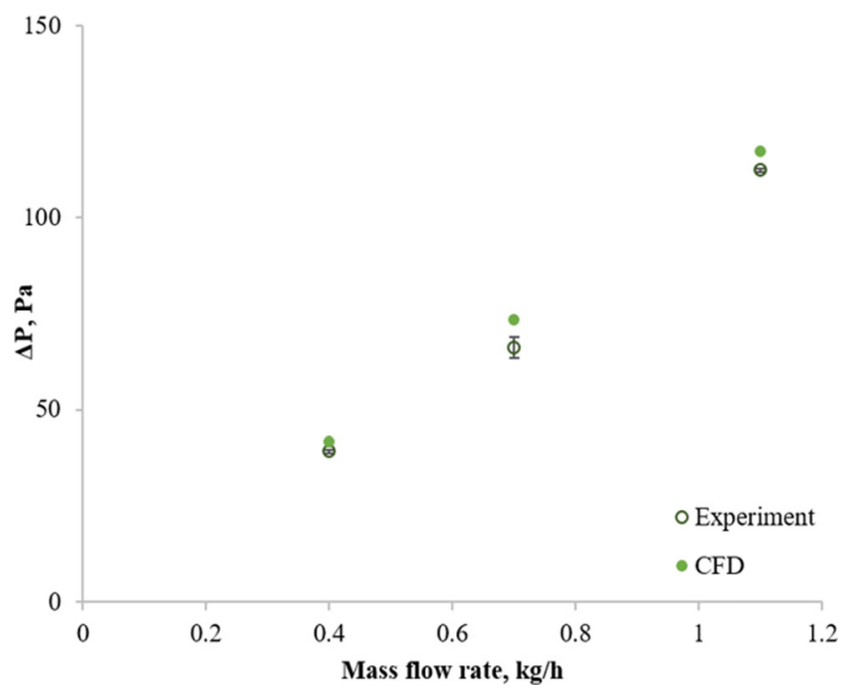

Fig. 8 Comparison of the experimental and numerical results for pressure drop of the honeycomb monolith at various flow rates and experimental results with a maximum of $3.5 \%$ error at the mass flow rate of $1.1 \mathrm{~kg} / \mathrm{h}$ is achieved.

\subsubsection{Validation of model for the lattice structures}

Validation study with respect to the obtained experimental results is performed to determine the accuracy of the model with lattice structures. The lattice substrate has a diameter of $25.4 \mathrm{~mm}$ with $61.3 \mathrm{~mm}$ length, pore diameter of $1.85 \mathrm{~mm}$, strut diameter of $0.65 \mathrm{~mm}$, specific surface area of $1480 \mathrm{~m}^{-1}$, and the porosity of 0.73 . Figure 10 shows the model validation of the pressure drop for lattice substrate with varying mass flow rate $(0.7-1.8 \mathrm{~kg} / \mathrm{h})$ and constant inlet gas temperature of $923 \mathrm{~K}$. The pressure drop linearly increases with the flow rate and at the highest flow rate examined $(1.8 \mathrm{~kg} / \mathrm{h})$ is $78 \mathrm{~Pa}$ as seen in Fig. 10. The linear dependence is expected in the examined mass flow rate range where the maximum inlet velocity at the highest mass flow rate is equal to $1.6 \mathrm{~m} / \mathrm{s}$. Exponential trend for lattice structures is observed in literature for higher velocities $[14,58,59]$. The numerical model over predicts the pressure drop values for 0.7 and $1.1 \mathrm{~kg} / \mathrm{h}$, but slightly under predicts the value at the highest flow rate (1.8 $\mathrm{kg} / \mathrm{h}$ ) by $1.6 \%$. The percentage error between the experimental and numerical data is decreasing with the increase of the mass flow rate. Higher percentage error between the lowest flow rate pressure drop obtained by experiment and simulation of $13.7 \%$ is explained by possible instrument uncertainty in the given range. Namely, the value of pressure drop in the experiment is $22 \mathrm{~Pa}$ while the differential pressure device has a maximum error of $5 \%$ in the instrument range. This observation is assumed to be correct owing to the reduction of percentage error with the increase of the mass flow rate. The numerical results for pressure drop agree well with the experimentally measured pressure drop.

The same validation approach as in the honeycomb model has been applied for the temperature distribution. Figure 11 shows the temperature distribution along the axial length of the lattice substrate, at the centre $\left(T_{1}, T_{3}, T_{5}\right)$ as well as the surface $\left(T_{2}, T_{4}, T_{6}\right)$, at mass flow rate of $1.1 \mathrm{~kg} / \mathrm{h}$. Note that the error bars lie within the point. Maximum temperature is located at the inlet centre of the lattice substrate with a value of 922 $\mathrm{K}$, whereas the lowest temperature is located at the exit outer surface with a value of $694 \mathrm{~K}$. The predicted temperatures calculated with the numerical model follow the same trend as in the experiments. The highest temperature values are located in the inlet centre of the sample, whereas the lowest temperatures are located towards the outer surface of the sample. Heat losses to the surroundings cause the radial temperature gradient in the lattice substrate, the same as for the honeycomb substrate. The axial gradient from the inlet centre to the exit centre is around $\Delta T_{\mathrm{T} 1-\mathrm{T} 5}=66 \mathrm{~K}$ for the lattice substrate, $20 \%$ lower than for the honeycomb substrate. Generally, the numerical data is closely matched with the 


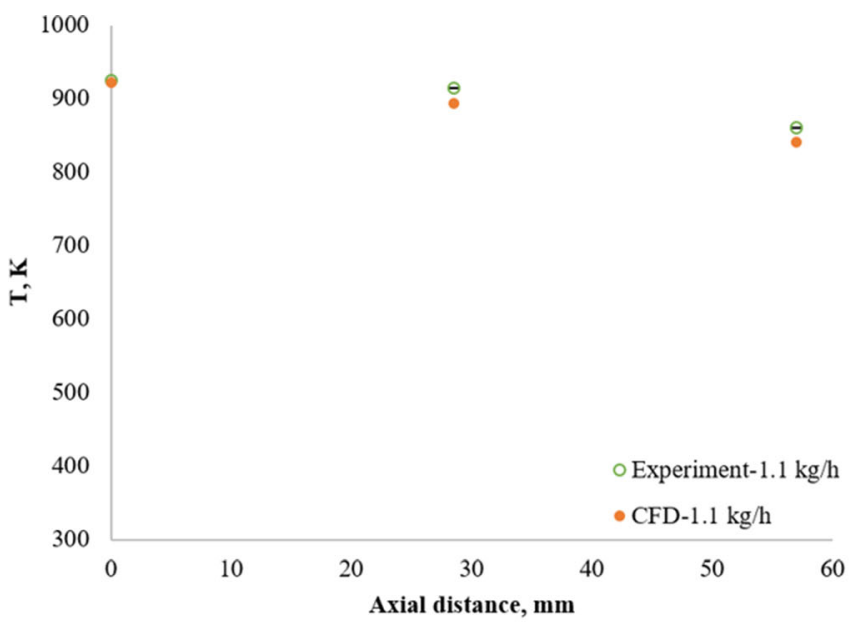

a

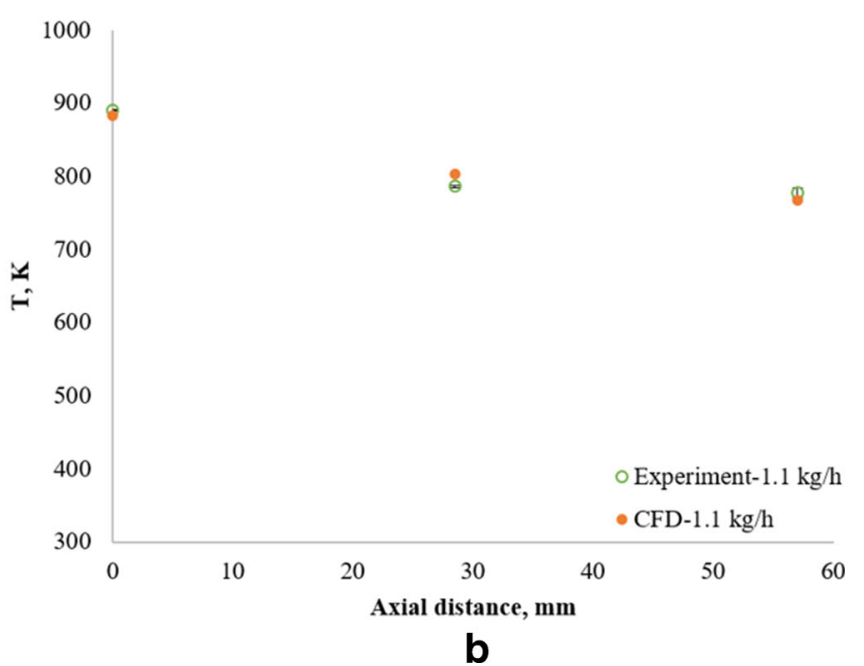

Fig. 9 Comparison of the experimental and numerical results for temperature distribution along the honeycomb monolith. a Centre points $\left(T_{1}, T_{3}, T_{5}\right)$ and $\mathbf{b}$ surface points $\left(T_{2}, T_{4}, T_{6}\right)$ at the mass flow rate of $1.1 \mathrm{~kg} / \mathrm{h}$

experimental data with the highest discrepancy of $9.6 \%$ between the calculated and measured temperatures.

Numerical models have been validated for the benchmark honeycomb substrate and the lattice substrate. For the honeycomb model, the pressure drop can be predicted with a maximum error of less than $10 \%$ and the predicted temperatures show a deviation of approximately $4 \%$ from the experimental results. Lattice model can predict the pressure drops with a maximum error below $14 \%$ in the studied range, while the temperatures show a maximum deviation of less than $10 \%$ from the experimental results. Both models show good agreement with the experiment.

\subsection{Comparison between the honeycomb and lattice designs with the same cell density}

CFD model has been validated for a lattice with pore diameter $\left(d_{\mathrm{p}}\right)$ of $1.85 \mathrm{~mm}$, although the DLP technology is superior to

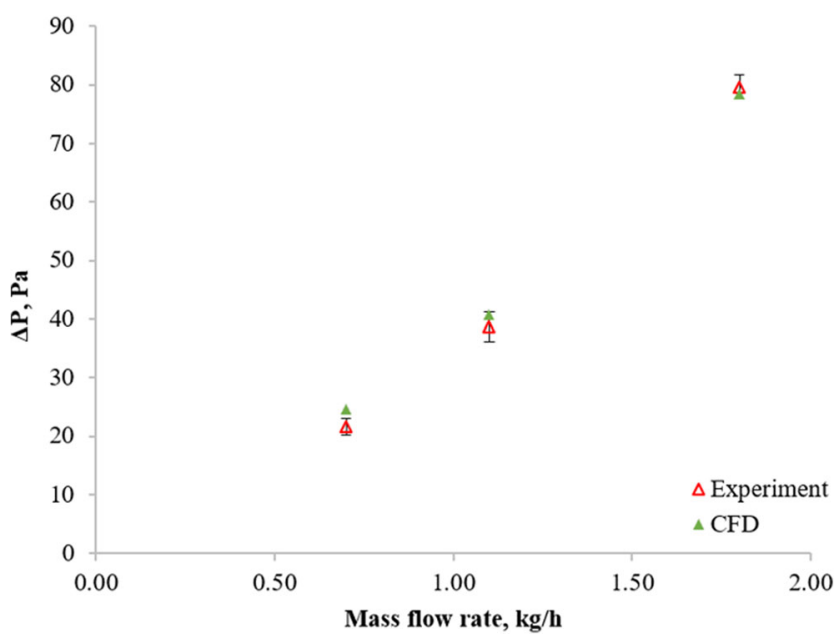

Fig. 10 Comparison of the experimental and numerical results for pressure drop of the lattice structure for various mass flow rates
SLA for manufacturing of complex geometries, the ceramic slurry formulation needs to be optimised for a successful print with thinner struts and smaller cell sizes. However, to have a fair comparison between the honeycomb and the lattice design, the same cell density is investigated with the validated numerical model. Square channelled honeycomb monolith with 400 CPSI and $0.2 \mathrm{~mm}$ thick walls was chosen as the benchmark. The investigated lattice has identical pore diameter of $1.05 \mathrm{~mm}$ as the honeycomb, with strut diameter of 0.2 $\mathrm{mm}$, porosity of 0.87 , and specific surface area of $2062 \mathrm{~m}^{-1}$. The diameter and the length of both models were kept the same to rule out any dimensional effects. The corresponding values are $12.5 \mathrm{~mm}$ and $57 \mathrm{~mm}$ for diameter and length, respectively.

\subsubsection{Velocity}

In the actual honeycomb channels, the velocity is affected by the flow maldistribution, consequently affecting the residence time and conversion efficiency, resulting in utilization of only a part of the substrate $[10,60]$. Research has found that the reactions do not influence the flow distribution as much as the heat loss to the surroundings [10]; therefore, it is feasible to study the flow distribution in non-reactive conditions. It has similarly been determined that the heat losses cause variations in temperature profile in the monolith [61]. The velocity flow field is likely to present some essential differences between honeycomb monoliths and lattices. Below, we investigate the differences in the air flow velocity field between the honeycomb and the lattice.

Figures $12 \mathrm{a}$ and $\mathrm{b}$ show the air velocity contours at mass flow rate of $1.1 \mathrm{~kg} / \mathrm{h}$ for both honeycomb and lattice substrates. According to the Fig. 12a, the incoming air flow velocity increases instantly after entering the honeycomb channels due to the reduction in the cross-sectional area. As 


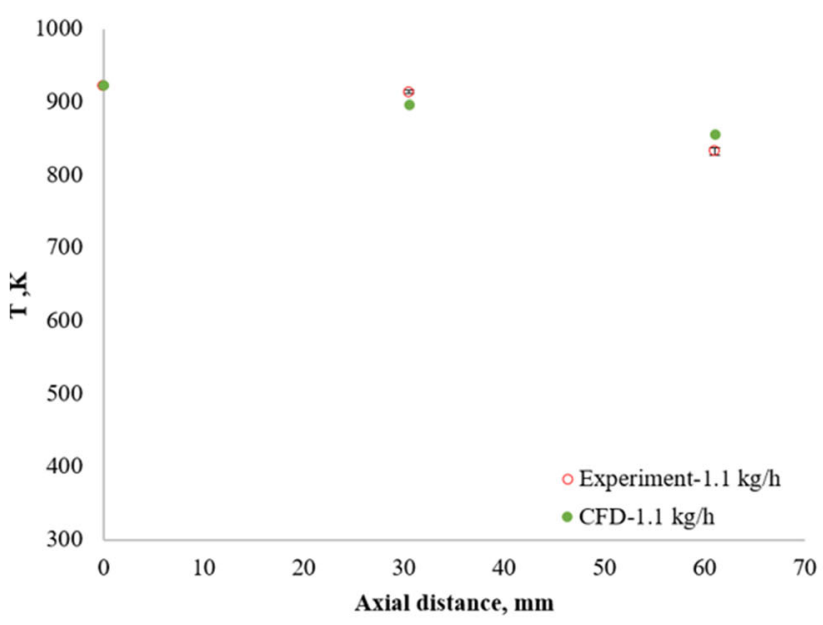

a

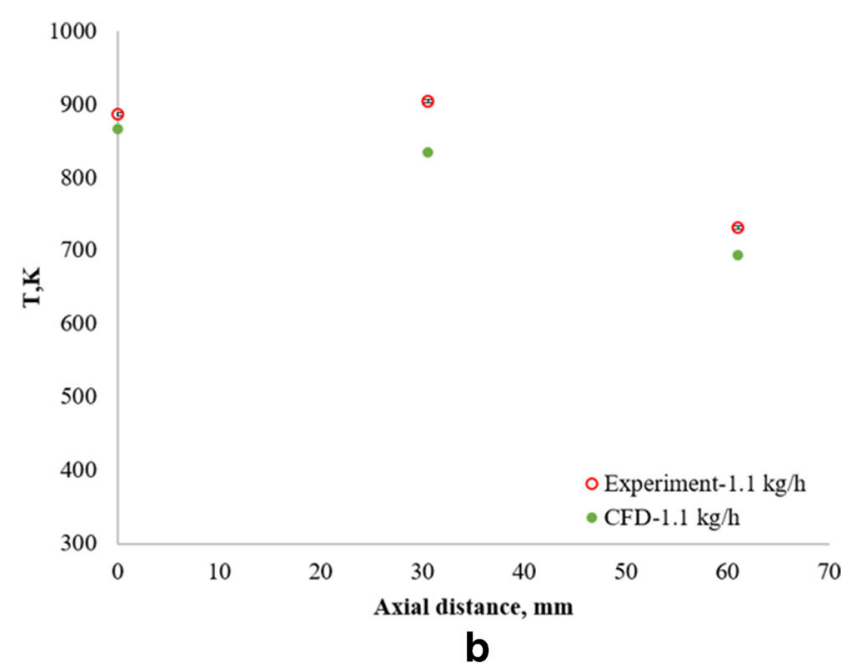

Fig. 11 Temperature in the a centre $\left(T_{1}, T_{3}, T_{5}\right)$ and $\mathbf{b}$ surface $\left(T_{2}, T_{4}, T_{6}\right)$ of the lattice at the mass flow rate of $1.1 \mathrm{~kg} / \mathrm{h}$

expected, each channel exhibits parabolic velocity profile with the maximum velocity at the centre of the channel and zero at the walls of the channels [10]. The velocity increases to the highest velocity of $4.02 \mathrm{~m} / \mathrm{s}$ in the centre of the channel for the flow rate of $1.1 \mathrm{~kg} / \mathrm{h}$. As opposed to the single-channel model, generally used to model the monolith flow behaviour, the channels do not show identical velocity profile [10]. Channels close to the periphery of the substrate show higher maximum velocity than the channels in the centre of the sample due to the fluid's physical properties at the periphery. Since the air is treated as compressible fluid, the specific volume decreases along the channel length due to the decrease in temperature causing the decrease in the average velocity in axial direction in the substrates.

Figure $12 \mathrm{~b}$ presents the velocity field contour for the lattice. The flow distribution can be explained as a combination of external flow around cylinders and internal flow between the lattice cells. Flow path in the lattice becomes tortuous
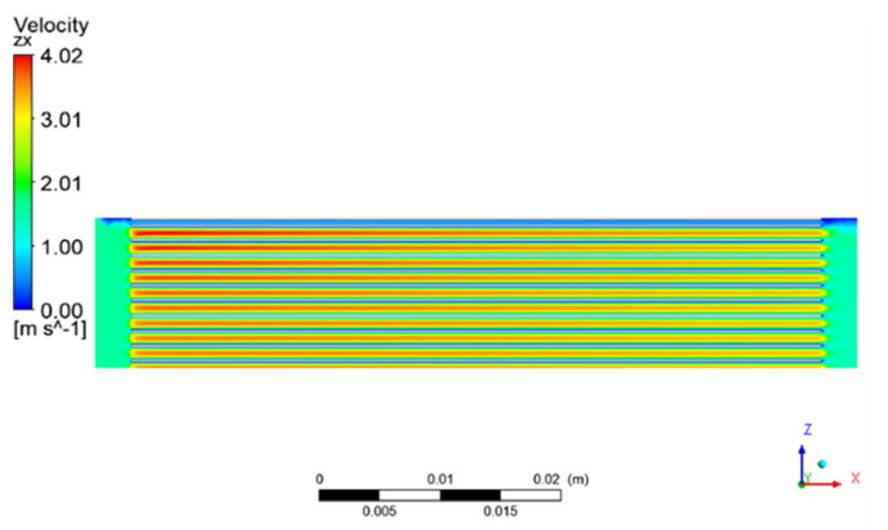

a

Fig. 12 Velocity field contour for the a 400 CPSI honeycomb at the inlet mass flow rate of $1.1 \mathrm{~kg} / \mathrm{h}$ (ZX plane). b Velocity field contour for the lattice at the inlet mass flow rate of $1.1 \mathrm{~kg} / \mathrm{h}(\mathrm{ZX}$ plane $)$

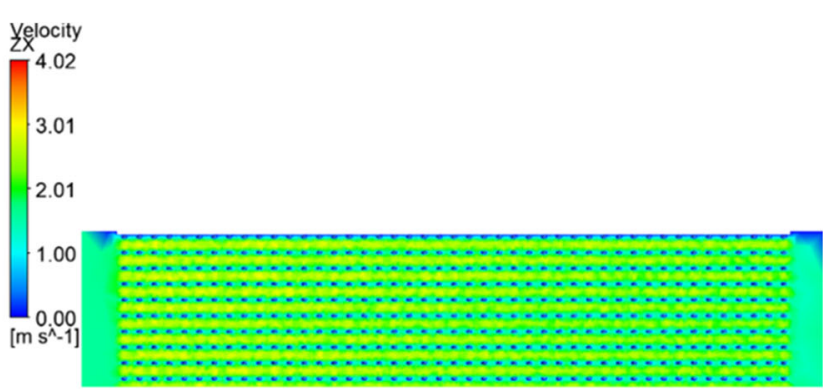

where the velocity of the fluid changes rapidly as the fluid comes in contact with the lattice struts [59]. The struts of the lattice present resistance to the fluid flow with forward stagnation point and wake region behind the strut. Maximum velocity is observed in between the lattice cells with a value of $3.08 \mathrm{~m} / \mathrm{s}$. The overall lower velocity values in the lattice can benefit the efficiency of the substrate due to the increase of the residence time of the flow in the substrate and increased flow to solid interaction. Moreover, the reduction of the overall velocity could have an influence on the thermal degradation of the substrate brick and pressure drop decrease across the entire substrate [62].

\subsubsection{Pressure drop}

Reliable comparison of the back-pressure between the lattice and honeycomb sample is achieved using the values of normalized pressure drop presented as pressure drop over length

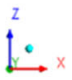

\section{b}




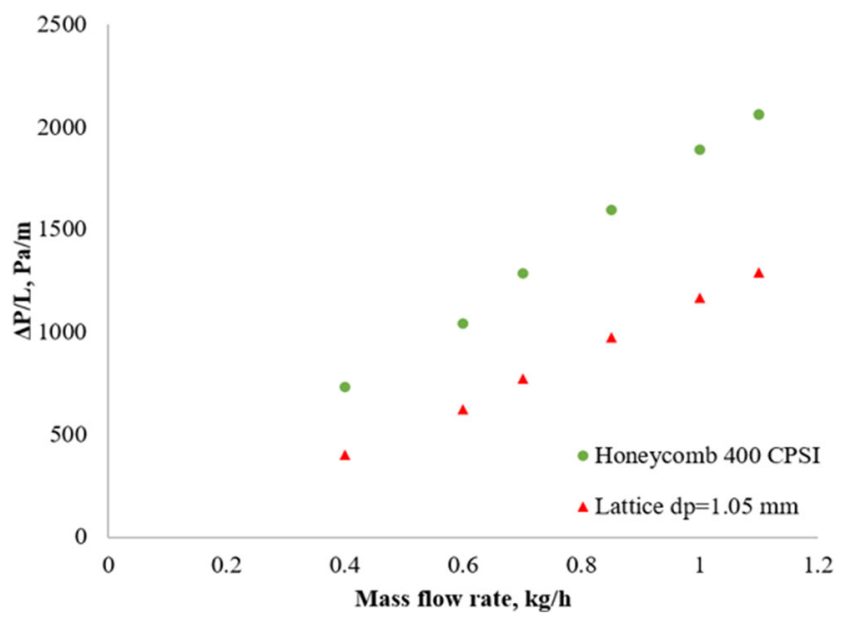

Fig. 13 Normalized pressure drops versus mass flow rate for 400 CPSI $\mathrm{HC}$ and lattice with $d_{\mathrm{p}}=1.05 \mathrm{~mm}$

of the sample. The comparison of the pressure drop for a lattice with the same pore density as the benchmark honeycomb is shown in Fig. 13. In the mass flow rate range of interest, the pressure drop of the honeycomb varies linearly with the mass flow rate $[47,56,62]$. Considering the flow in the honeycomb channels is fully laminar, the viscous effects are the main contributor to the pressure drop in the studied mass flow rate range [60]. Furthermore, the pressure drop follows the same linear trend in the examined mass flow rate range for the lattice structure. In contrast to the honeycomb substrate, the pressure drop across the $d_{\mathrm{p}}=1.05 \mathrm{~mm}$ lattice is about $38-45 \%$ lower. The lower pressure drop is a consequence of the higher porosity of the lattice. Namely, the higher porosity significates that the void fraction, which is available for the fluid flow, in the lattice structure is higher. Similarly, lower pressure drop with respect to the honeycomb, at low mass flow rates, has been observed in literature for open cell substrates with a porosity of 0.95 [14].

\subsubsection{Thermal properties}

It is expected that the tortuous pathway of the lattice substrate can enhance the heat transfer and minimize the manifestation of hot spots that cause catalyst deactivation. Interconnected solid struts in the internal structure of the lattice structure allow cross-mixing of the flow leading to an augment of the heat transfer [63]. The studies demonstrate that flow distribution within the honeycomb has an immense influence on the distribution of temperature and species concentration in the substrate [64]. Therefore, thermal properties of the honeycomb and lattice were investigated.

Figure 14 shows the temperature distribution contours with $1.1 \mathrm{~kg} / \mathrm{h}$ mass flow rate for honeycomb and lattice substrate. In case of the honeycomb, as seen in Fig. 14a, the area with the peak temperature, equal to the temperature of the incoming gas, is located in the central region of the substrate. The contour shown for honeycomb implies that by increasing the axial distance, the temperature gradient from the inlet face to the outlet face increases. Decrease of the temperature radially to the direction of the surface of the substrate is a consequence of the heat losses to the ambient $[1,10,64]$. The shape of the peak temperature region shows a downward slope in axial direction indicating the highest heat transfer in the inlet central region of the honeycomb. On the other hand, as shown in Fig. $14 \mathrm{~b}$, the diamond lattice has a more uniform temperature distribution at the whole core region in the axial direction indicating the higher heat transfer caused by less thermal mass. The peak temperature region has a downward slope trend from the inlet to the exit region.

The channel flow and the presence of the solid walls in the honeycomb cause limitations in radial heat transport. In contrast, the solid material of the honeycomb substrate increases thermal resistance and causes higher temperatures towards the substrate's outer surface. The same temperature distribution trend is expected at lower inlet temperatures. Further

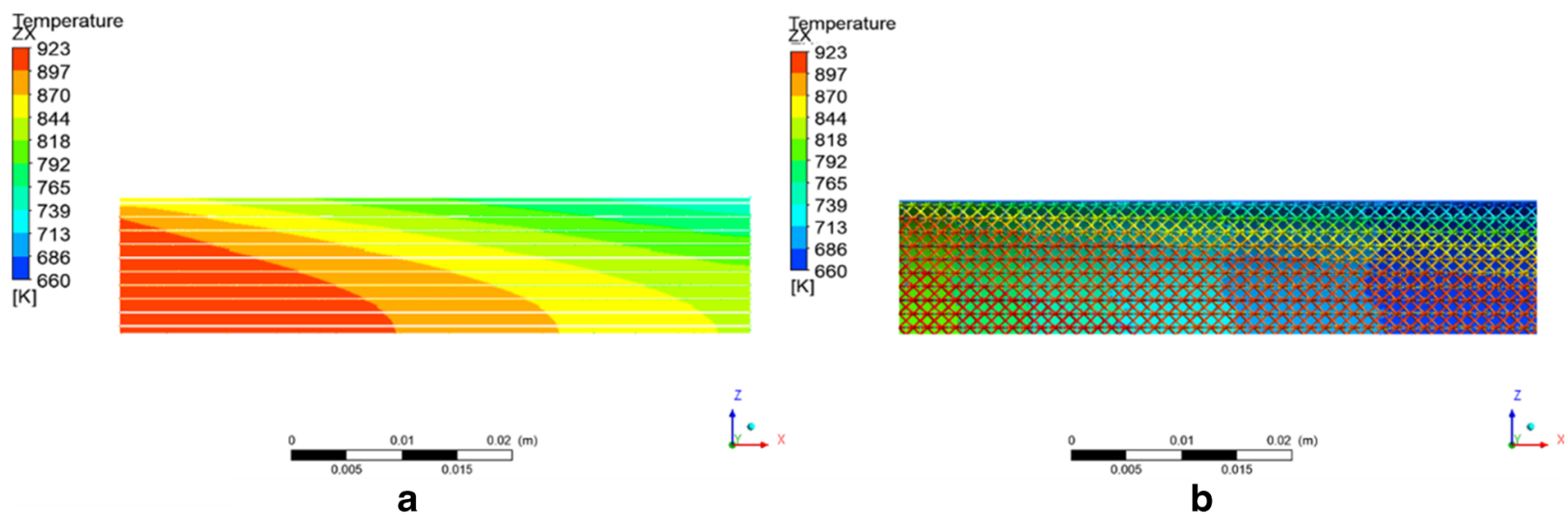

Fig. 14 Temperature contour of a honeycomb with 400 CPSI cell density and $0.2 \mathrm{~mm}$ walls and $\mathbf{b}$ diamond lattice with $1.05 \mathrm{~mm}$ pore diameter and $0.2 \mathrm{~mm}$ strut diameter at mass flow rate of $1.1 \mathrm{~kg} / \mathrm{h}$ 
optimization of the lattice design is needed to obtain higher temperatures at the outer surface of the substrate.

It can be concluded that the lattice substrate performed better thermally and hydraulically. The predictions of the pressure gradient presented the same trend in which the pressure drop across the lattices is lower regardless of the increase of the mass flow rate as compared with the benchmark honeycomb in the studied range. This pressure drop study indicates that utilizing the lattice design is significantly more efficient due to the lower pressure drop and lower average velocity in comparison with the 400 CPSI HC. The $d_{\mathrm{p}}=1.05 \mathrm{~mm}$ lattice substrate showed improvement in the thermal performance showing lesser axial temperature gradients in the core of the substrate. The lower temperature at the periphery of the lattice is a consequence of the lower amount of solid phase causing higher heat dissipation to the surroundings. Hence, the lattice design should be optimized to achieve higher temperatures at the outer surface.

\subsection{Effect of the lattice design on the substrate performance}

The main parameters of the lattice are the strut diameter $\left(d_{\mathrm{s}}\right)$, strut length $\left(L_{\mathrm{s}}\right)$, cell length $\left(L_{\mathrm{c}}\right)$, pore diameter $\left(d_{\mathrm{p}}\right)$, porosity $(\varepsilon)$, and the specific surface area $\left(S_{\mathrm{v}}\right)$. The strut diameter affects the porosity, the specific surface area of the substrate as well as the mechanical strength. If the volume of the substrate is to be constant, the feasible increase of the lattice porosity is achievable by increasing the pore size. Should the pore size be double, samples with porosity up to 0.94 are achievable. Doubling the pore size, on the other hand, decreases the surface area by half. The specific surface area $\left(S_{\mathrm{v}}\right)$ of the lattice substrate has a large influence on the resulting temperature profile [65]. Current improvements in the ceramic additive manufacturing could allow fabrication of strut diameters as low as $0.2 \mathrm{~mm}$. The strut diameter in this study was varied from 0.2 to $0.65 \mathrm{~mm}$, covering a wide range of substrate porosities. Table 2 presents the main geometrical properties of the studied lattice structures.

Figures $15 \mathrm{a}$ and $\mathrm{b}$ show the effect of the strut diameter on the specific surface area and the effect of porosity of the diamond lattices on the specific length ratio. Specific surface area

Table 2 Main geometrical properties of the lattice structures

\begin{tabular}{llllll}
\hline$\varepsilon,-$ & $d_{\mathrm{s}}, \mathrm{mm}$ & $d_{\mathrm{p}}, \mathrm{mm}$ & $L_{\mathrm{c}}, \mathrm{mm}$ & $L_{\mathrm{s}}, \mathrm{mm}$ & $S_{\mathrm{v}}, \mathrm{m}^{-1}$ \\
\hline 0.94 & 0.2 & 2 & 2.2 & 1.56 & 950 \\
0.90 & 0.3 & 2 & 2.3 & 1.63 & 1090 \\
0.79 & 0.5 & 2 & 2.5 & 1.77 & 1290 \\
0.73 & 0.65 & 2 & 2.65 & 1.87 & 1333 \\
\hline
\end{tabular}

increases with the increase of the strut diameter as pictured in Fig. 15a. As an overall trend, the specific surface increased with increasing the cell size and strut thickness at constant pore diameter. The specific length ratio, $\Phi$, representing the ratio of pore diameter and strut thickness is plotted against porosity in Fig. 15b. As the specific length ratio increases, the porosity of the sample increases because the strut diameter becomes smaller compared with the pore diameter [13].

Figure 16 shows the effect of the lattice porosity ( $x$-axis) on the specific surface area (blue bars) and pressure drop (yellow bars). With the decrease of the porosity, specific surface area and pressure drop values increase. The lowest pressure drop of $269 \mathrm{~Pa} / \mathrm{m}$ is observed for lattice porosity of 0.94 , whereas the highest pressure drop of $579 \mathrm{~Pa} / \mathrm{m}$ is observed for the lattice porosity of 0.73 . The results show that the pressure drop is inversely proportional to the porosity, which is in agreement with the literature [27]. On the other hand, the specific surface area of the lattice increases by $29 \%$ with the decrease of the porosity from 0.94 to 0.73 . The increase of the surface area caused by the increase of the strut diameter at constant pore diameter results in a decrease of the porosity [27]. As a drawback of the increase of the surface area and the decrease of the porosity, the pressure drop increases. From the results presented in Fig. 16, it can be concluded that the pressure drop is directly proportional to the specific surface area.

Since the increase of the strut diameter increases the amount of the solid phase, the strut diameter increase is expected to have an influence on the heat transfer. Therefore, a study of the strut thickness increase on the temperature distribution is conducted in the following section. The strut diameter was varied from 0.2 to $0.65 \mathrm{~mm}$ resulting in a decrease of the substrate porosity at constant pore diameter as shown in Table 2.

In Fig. 17, one can see the result of the increasing strut thickness on temperature distribution in lattice substrate at the inlet mass flow rate of $1.1 \mathrm{~kg} / \mathrm{h}$. Figure $17 \mathrm{a}$ illustrates the temperature contour for the lattice with a strut diameter of 0.2 $\mathrm{mm}$. This design has the least surface area of $950 \mathrm{~m}^{-1}$ and the highest porosity of 0.94 among all substrates. The temperature distribution in the solid is uniform throughout the whole core area with steep radial gradients due to the heat loss boundary on the outer surface wall of the lattice. The lowest temperatures are present in the periphery of the substrate as a result of less solid material in the radial direction. Similarly, low axial temperature gradients in the core of the substrate are seen for the lattice with $d_{\mathrm{s}}=0.3 \mathrm{~mm}$ (Fig. 17b), with sharp radial gradients towards the substrate's periphery. In comparison, the temperatures are slightly higher at the periphery of the substrate with $d_{\mathrm{s}}=0.3 \mathrm{~mm}$ than with $d_{\mathrm{s}}=0.2 \mathrm{~mm}$ due to the thicker outer mat providing more resistance to the external heat loss. Further increase of the strut diameter to $0.5 \mathrm{~mm}$ (Fig. 17c) causes the increase of the axial temperature gradients. On the other hand, the temperature at the periphery of the 

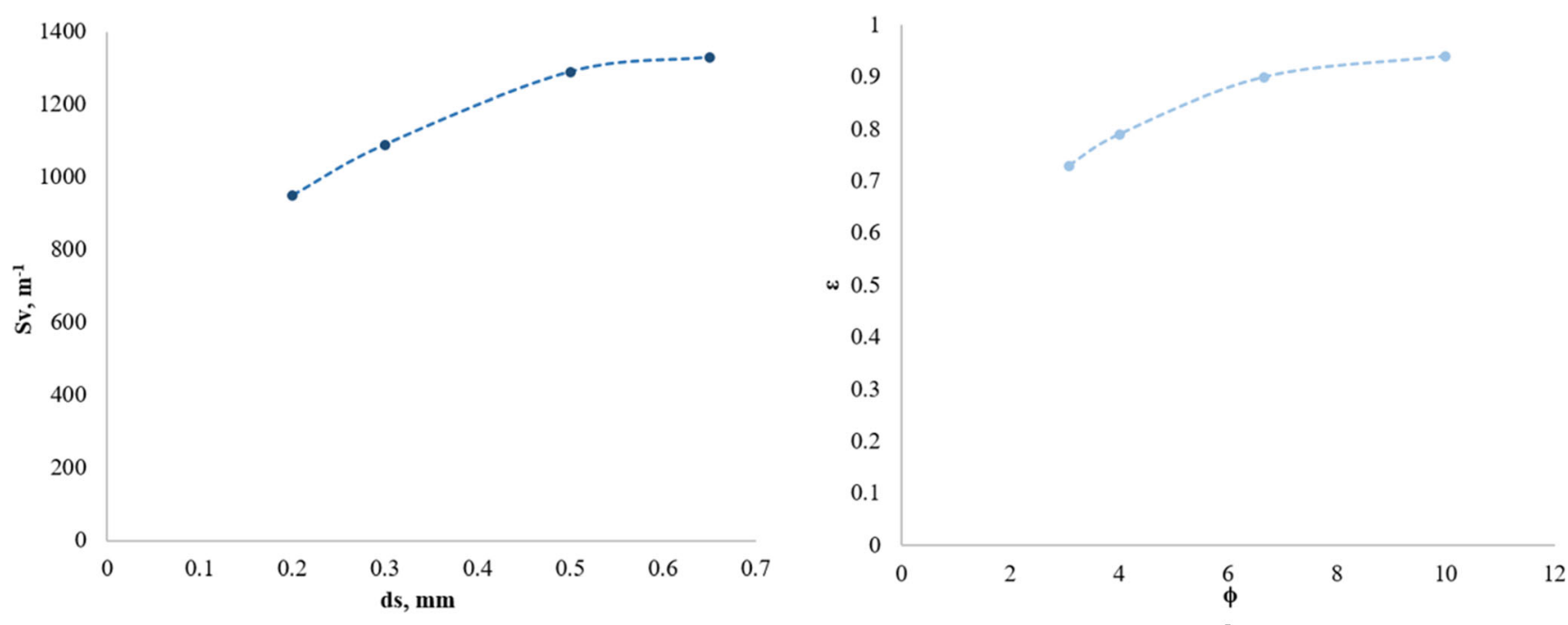

a

b

Fig. 15 a Effect of the strut diameter on the specific surface area. $\mathbf{b}$ Effect of the porosity on the specific length ratio

sample is higher when compared with substrates with $d_{\mathrm{s}}=$ $0.2 \mathrm{~mm}$ and $d_{\mathrm{s}}=0.3 \mathrm{~mm}$. The lowest uniformity of temperature in the core of the substrate is apparent when the strut thickness value is $0.65 \mathrm{~mm}$ (Fig. 17d). The substrate with $d_{\mathrm{s}}$ $=0.65 \mathrm{~mm}$ has the lowest porosity of 0.73 , hence the highest amount of solid material present in the substrate volume. The increase of the strut diameter results in the decrease of the void to solid ratio. Additionally, the higher the amount of solid, the poorer the heat transfer to the solid resulting in higher temperature gradients. The highest axial temperature gradients are thereupon observed with the highest strut thickness. The velocity in between the lattice cells for the larger strut diameter is higher resulting in a decrease of the residence time in the lattice following a decrease in total heat transfer. From the presented contours, it can be concluded that the increase of the heat exchange surface formed by the increase of the strut diameter increases the temperature gradient over the core region. Nevertheless, the increase of the solid phase has a positive influence on the temperatures in the substrate's periphery. This improvement indicates a possibility of more effective utilization of the heat within the lattice by tailoring the lattice design and strut thickness where necessary.
Fig. 16 Effect of the porosity of the lattice on the pressure drop and specific surface area

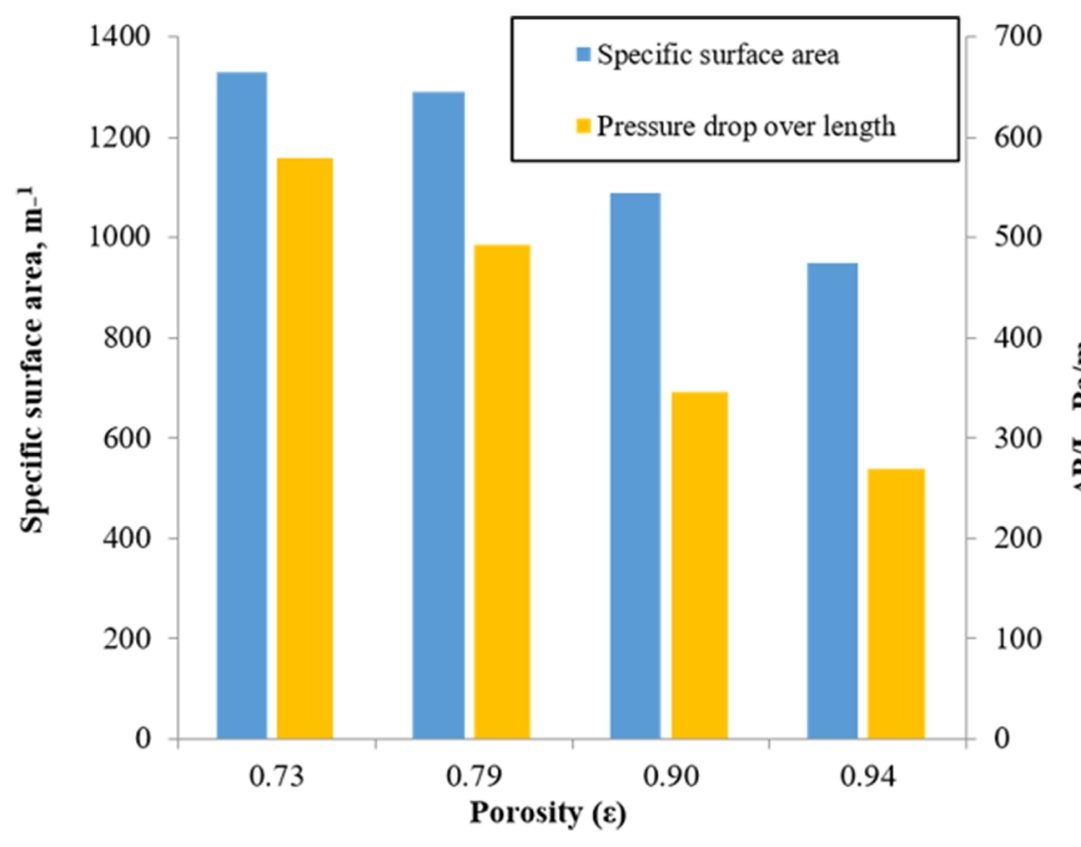



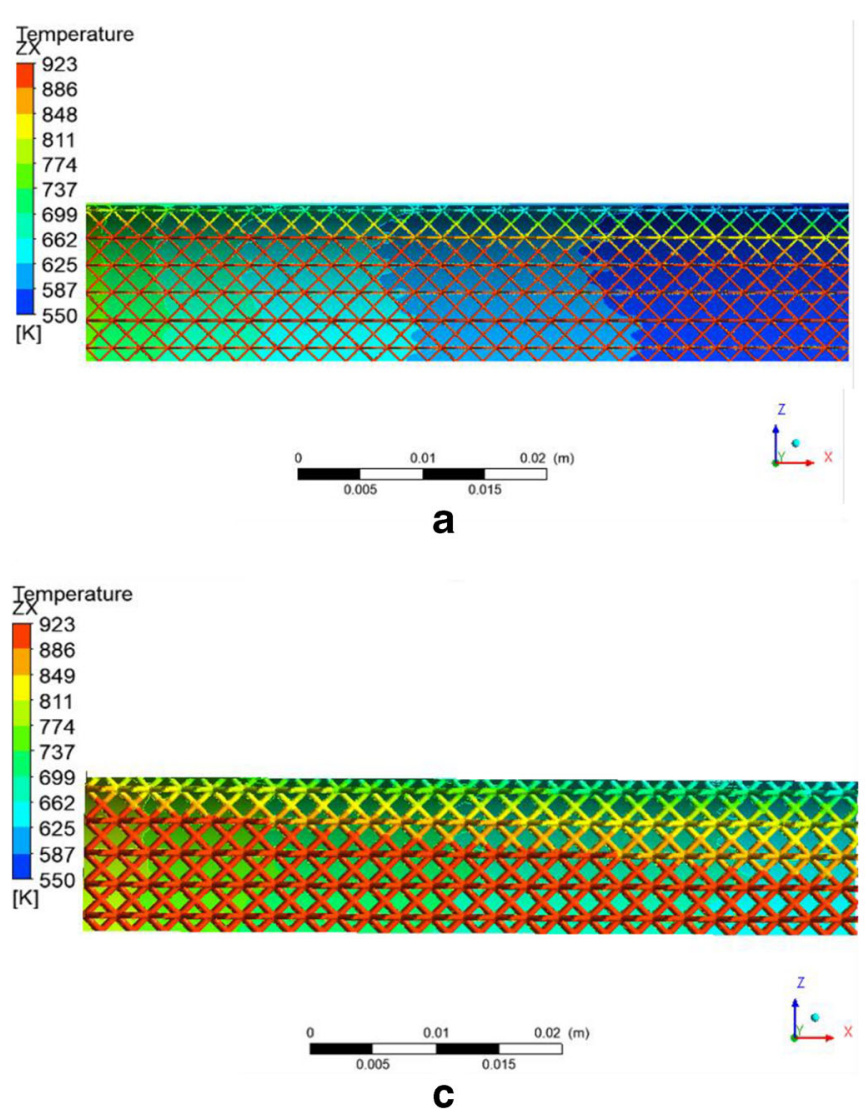

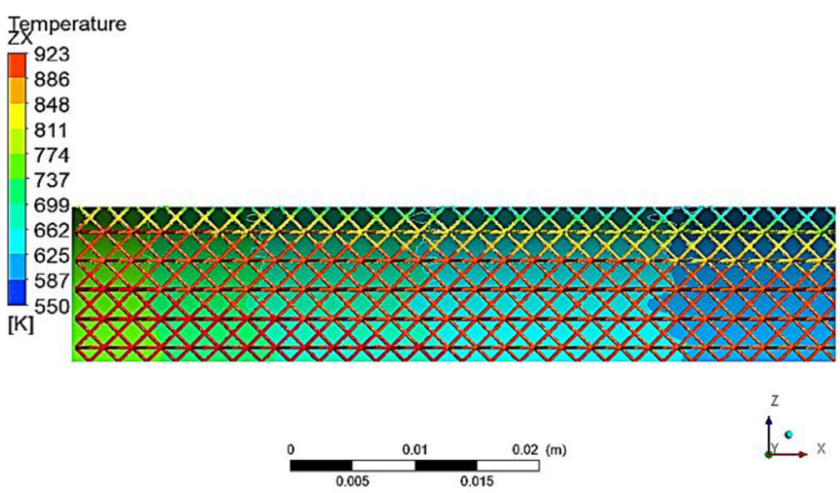

b
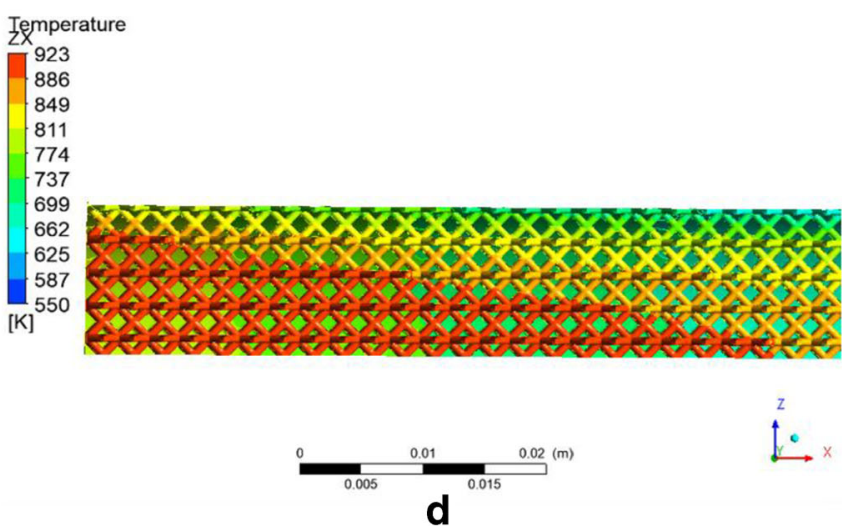

Fig. 17 Temperature distribution along the lattice substrate at different strut diameters and constant flow rate of $1.1 \mathrm{~kg} / \mathrm{h}$ a $d_{\mathrm{s}}=0.2 \mathrm{~mm} \mathbf{b} d_{\mathrm{s}}=0.3 \mathrm{~mm}, \mathbf{c}$ $d_{\mathrm{s}}=0.5 \mathrm{~mm}, \mathbf{d} d_{\mathrm{s}}=0.65 \mathrm{~mm}$

As described earlier, one of the key design requirements for the monolith substrates is high surface area and low pressure drop. When judging the efficiency of the substrate, priority can be given to higher surface area to increase the conversion efficiency, however with a penalty of increased pressure loss. The increase of the strut diameter results in the increase of the specific surface area due to the additional solid material present in the substrate; however, the additional exposed surface slightly increases the pressure drop and the temperature gradients. The judgement on the optimal strut thickness must be made considering the environment in which the substrate will be used. The substrate with thicker struts and lower pore density could be retaining more heat during cooling periods because of the higher thermal inertia, whereas the substrate with thinner strut diameter and higher pore density possesses higher surface area and possibility of a quicker warm up.

\section{Conclusions}

In this study, an additively manufactured ceramic diamond lattice substrate has been proposed to overcome the limitations of the conventional honeycomb substrate. DLP additive manufacturing technology has been successfully used to manufacture the diamond lattice substrate. The comparison of the honeycomb design and the diamond lattice has been achieved by pairing numerical simulations and experimental studies with additive manufacturing. The effect of the cell size and strut diameter on the geometric characteristics as well as pressure drop and temperature distribution were studied through numerical simulations.

The key findings of this study may be summarized as follows:

- DLP additive manufacturing technology enables fabrication of self-supported ceramic diamond lattice substrates.

- As an overall trend, the specific surface area of the lattice increases with increasing the cell size and strut thickness at constant pore diameter. As a consequence, the increase of the surface area results in a decrease of the porosity which results in the increase of the pressure drop.

- The pressure drop across the diamond lattices is lower regardless of the lattice pore size as compared with the honeycomb, with a decrease of up to $80 \%$, but with a penalty of lower surface area.

- The lattice with a pore size of $1.05 \mathrm{~mm}$ and strut thickness of $0.2 \mathrm{~mm}$ with a similar surface area as the honeycomb substrate, demonstrates a decrease of pressure drop by 38 $45 \%$ at studied flow rates. 
- Diamond lattices exhibit lower axial temperature gradients for all porosities examined. The lattices display homogeneous temperature distribution at the core area relative to the conventional honeycomb design, indicating the higher heat transfer properties caused by the tortuosity of the flow and the ability of flow exchange in both radial and axial direction. This improvement indicates a possibility of more effective utilization of the heat within the lattice.

The reduction of the back-pressure could have a positive impact on the fuel economy, while the improved core temperature distribution allows to conclude that the lattice structure could have better thermal performance in the exhaust system. The findings present potential for improvement of the design of the ceramic catalytic supports by utilization of DLP additive manufacturing technology. The diamond lattice could be specifically tailored to yield desired temperature distribution and pressure drop by controlling the strut diameter and cell size. Further design improvement of the diamond lattice is needed to obtain higher temperatures at the periphery of the substrate, as well as coating and testing with the actual exhaust gas to get the insights on the conversion efficiency and warmup/cool down behaviour of the diamond lattice structures.

Authors' contributions Methodology, formal analysis, investigation, data curation, writing - original draft: Nikolina Kovacev; investigation, methodology: Sheng Li; methodology: Soheil Zeraati-Rezaei; writing - review \& editing, supervision: Hassan Hemida; writing - review \& editing, supervision: Athanasios Tsolakis; writing - review \& editing, supervision: Khamis Essa.

Funding The research leading to these results has received funding from the Engineering and Physical Sciences Research Council for project FACE - Novel Integrated Fuel Reformer-Aftertreatment System for Clean and Efficient Road Vehicles under grant number EP/P031226/1. N.K. received an award of a $\mathrm{PhD}$ scholarship from the University of Birmingham.

Data availability Data will be available upon request.

\section{Compliance with ethical standards}

Conflict of interest The authors declare that they have no conflict of interest.

Ethical approval Not applicable.

Consent to participate Not applicable.

Consent to publish Not applicable.

Code availability The commercial Ansys CFX code was used for the numerical model.

Open Access This article is licensed under a Creative Commons Attribution 4.0 International License, which permits use, sharing, adaptation, distribution and reproduction in any medium or format, as long as you give appropriate credit to the original author(s) and the source, provide a link to the Creative Commons licence, and indicate if changes were made. The images or other third party material in this article are included in the article's Creative Commons licence, unless indicated otherwise in a credit line to the material. If material is not included in the article's Creative Commons licence and your intended use is not permitted by statutory regulation or exceeds the permitted use, you will need to obtain permission directly from the copyright holder. To view a copy of this licence, visit http://creativecommons.org/licenses/by/4.0/.

\section{References}

1. Ibrahim HA, Ahmed WH, Abdou S, Blagojevic V (2018) Experimental and numerical investigations of flow through catalytic converters. Int J Heat Mass Transf 127:546-560. https://doi.org/ 10.1016/j.ijheatmasstransfer.2018.07.052

2. Shaw BT, Fischer GD, Hedrick JK (2002) A simplified coldstart catalyst thermal model to reduce hydrocarbon emissions. In: 15 th Triennial World Congress. IFAC, Barcelona, Spain, pp 307-312

3. Boger T, Heibel AK, Sorensen CM (2004) Monolithic catalysts for the chemical industry. Ind Eng Chem Res 43:4602-4611. https:// doi.org/10.1021/ie030730q

4. Williams JL (2001) Monolith structures, materials, properties and uses. Catal Today 69:3-9. https://doi.org/10.1016/S0920-5861(01) 00348-0

5. Govender S, Friedrich H (2017) Monoliths: a review of the basics, preparation methods and their relevance to oxidation. Catalysts 7: 62. https://doi.org/10.3390/catal7020062

6. Nijhuis TA, Beers AEW, Vergunst T, Hoek I, K F, Moulijn JA (2001) Preparation of monolithic catalysts. Stud Surf Sci Catal 43:345-380. https://doi.org/10.1016/S0167-2991(06)80901-8

7. Avila P, Montes M, Miró EE (2005) Monolithic reactors for environmental applications: a review on preparation technologies. Chem Eng J 109:11-36. https://doi.org/10.1016/j.cej.2005.02.025

8. Lachman IM, Williams JL, Park S (1992) Extruded monolithic catalyst supports. Catal Today 14:317-329

9. Chakravarthy VK, Conklin JC, Daw CS, D'Azevedo EF (2003) Multi-dimensional simulations of cold-start transients in a catalytic converter under steady inflow conditions. Appl Catal A Gen 241: 289-306. https://doi.org/10.1016/S0926-860X(02)00490-8

10. Agrawal G, Kaisare NS, Pushpavanam S, Ramanathan K (2012) Modeling the effect of flow mal-distribution on the performance of a catalytic converter. Chem Eng Sci 71:310-320. https://doi.org/10. 1016/j.ces.2011.12.041

11. Goralski CT, Chanko TB (2010) Modeling the effect of substrate cell shape on conversion in monolith catalysts. SAE Tech Pap Ser 1. https://doi.org/10.4271/2001-01-0932

12. Soltani S, Wang-Hansen C, Andersson R, Andersson B (2014) CFD characterization of monolithic reactors for kinetic studies. Can J Chem Eng 92:1570-1578. https://doi.org/10.1002/cjce. 22022

13. Busse C, Freund H, Schwieger W (2018) Intensification of heat transfer in catalytic reactors by additively manufactured periodic open cellular structures (POCS). Chem Eng Process Process Intensif 124:199-214. https://doi.org/10.1016/j.cep.2018.01.023

14. Papetti V, Dimopoulos Eggenschwiler P, Della Torre A, Lucci F, Ortona A, Montenegro G (2018) Additive Manufactured open cell polyhedral structures as substrates for automotive catalysts. Int $\mathrm{J}$ Heat Mass Transf 126:1035-1047. https://doi.org/10.1016/j. ijheatmasstransfer.2018.06.061

15. Santoliquido O, Bianchi G, Dimopoulos Eggenschwiler P, Ortona A (2017) Additive manufacturing of periodic ceramic substrates for 
automotive catalyst supports. Int J Appl Ceram Technol 14:1164 1173. https://doi.org/10.1111/ijac. 12745

16. Aslan B, Yildiz AR (2020) Optimum design of automobile components using lattice structures for additive manufacturing. Mater Test 62:633-639. https://doi.org/10.3139/120.111527

17. Ferrizz RM, Stuecker JN, Cesarano J, Miller JE (2005) Monolithic supports with unique geometries and enhanced mass transfer. Ind Eng Chem Res 44:302-308. https://doi.org/10.1021/ie049468r

18. Li Y, Chen S, Cai X, Hong J, Wu X, Xu Y, Zou J, Chen BH (2018) Rational design and preparation of hierarchical monoliths through 3D printing for syngas methanation. J Mater Chem A 6:5695-5702. https://doi.org/10.1039/c8ta01597j

19. von Rickenbach J, Lucci F, Dimopoulos Eggenschwiler P, Poulikakos D (2015) Pore scale modeling of cold-start emissions in foam based catalytic reactors. Chem Eng Sci 138:446-456. https://doi.org/10.1016/j.ces.2015.08.020

20. Heck RH, Wei J, Katzer JR (1974) The transient response of a monolithic catalyst support. Chem React Eng-II Adv Chem Ser 133:34-45

21. Chen J, Yang H, Wang N, Ring Z, Dabros T (2008) Mathematical modeling of monolith catalysts and reactors for gas phase reactions. Appl Catal A Gen 345:1-11. https://doi.org/10.1016/j.apcata.2008. 04.010

22. Pant A, Paramadayalan T (2013) Continuum computational fluid dynamics model of heat transfer in monolith converter. Energy Emiss Control Technol 1-13. https://doi.org/10.2147/eect.s44770

23. Cornejo I, Nikrityuk P, Hayes RE (2020) The influence of channel geometry on the pressure drop in automotive catalytic converters: model development and validation. Chem Eng Sci 212:115317. https://doi.org/10.1016/j.ces.2019.115317

24. Amirnordin SH, Seri S, Salim WSW, Rahman HA (2011) Pressure drop prediction of square-cell honeycomb monolith structure. Int Conf Environ Sci Eng 2011(8):281-285

25. Hayes RE, Fadic A, Mmbaga J, Najafi A (2012) CFD modelling of the automotive catalytic converter. Catal Today 188:94-105. https://doi.org/10.1016/j.cattod.2012.03.015

26. Lucci F, Della Torre A, Montenegro G, Dimopoulos Eggenschwiler P (2015) On the catalytic performance of open cell structures versus honeycombs. Chem Eng J 264:514-521. https:// doi.org/10.1016/j.cej.2014.11.080

27. Nie Z, Lin Y, Tong Q (2017) Numerical investigation of pressure drop and heat transfer through open cell foams with 3D LaguerreVoronoi model. Int J Heat Mass Transf 113:819-839. https://doi. org/10.1016/j.ijheatmasstransfer.2017.05.119

28. Falfari S, Micci G, Bianchi GM, Brusiani F, Montenegro G, Della TA, Onorati A (2016) Design of catalytic devices by means of genetic algorithm: comparison between open-cell foam and honeycomb type substrates. SAE Int J Engines 9. https://doi.org/10.4271/ 2016-01-0965

29. Lucci F, Della Torre A, von Rickenbach J, Montenegro G, Poulikakos D, Dimopoulos Eggenschwiler P (2014) Performance of randomized Kelvin cell structures as catalytic substrates: masstransfer based analysis. Chem Eng Sci 112:143-151 . https://doi. org/10.1016/j.ces.2014.03.023

30. Pusterla S, Barbato M, Ortona A, D'Angelo C (2012) Numerical study of cell morphology effects on convective heat transfer in reticulated ceramics. Int J Heat Mass Transf 55:7902-7910. https://doi.org/10.1016/j.ijheatmasstransfer.2012.08.013

31. Ferrari L, Barbato MC, Ortona A, Angelo CD (2014) Convective heat transfer in cellular ceramic: a 3D numerical solution. In: 10th International Conference on Heat Transfer, Fluid Mechanics and Thermodynamics (HEFAT 2014). Orlando, Florida, pp 476-481

32. Kumar V, Manogharan G, Cormier D (2009) Design of periodic cellular structures for heat exchanger applications. Proc Solid Free Fabr Symp Texas 738-748
33. Gök A, Demirci HI, Gök K (2014) Determination of experimental, analytical, and numerical values of tool deflection at ball end milling of inclined surfaces. Proc Inst Mech Eng E J Process Mech Eng 230:111-119. https://doi.org/10.1177/0954408914540633

34. Gök A (2017) 2D numeric simulation of serrated-chip formation in orthogonal cutting of AISI316H stainless steel. Mater Technol 51: 953-956. https://doi.org/10.17222/mit.2017.038

35. Martínez S, Lamikiz A, Ukar E, Calleja A, Arrizubieta JA, Lopez de Lacalle LN (2017) Analysis of the regimes in the scanner-based laser hardening process. Opt Lasers Eng 90:72-80. https://doi.org/ 10.1016/j.optlaseng.2016.10.005

36. Essa K, Sabouri A, Butt H, Basuny FH, Ghazy M, El-Sayed MA (2018) Laser additive manufacturing of 3D meshes for optical applications. PLoS One 13:4-11. https://doi.org/10.1371/journal. pone.0192389

37. Sabouri A, Yetisen AK, Sadigzade R, Hassanin H, Essa K, Butt H (2017) Three-dimensional microstructured lattices for oil sensing. Energy Fuel 31:2524-2529. https://doi.org/10.1021/acs. energyfuels.6b02850

38. Elsayed M, Ghazy M, Youssef Y, Essa K (2019) Optimization of SLM process parameters for Ti6Al4V medical implants. Rapid Prototyp J 25:433-447. https://doi.org/10.1108/RPJ-05-2018-0112

39. Zocca A, Colombo P, Gomes CM, Günster J (2015) Additive manufacturing of ceramics: issues, potentialities, and opportunities. J Am Ceram Soc 98:1983-2001. https://doi.org/10.1111/jace. 13700

40. Li X, Zhong H, Zhang J, Duan Y, Bai H, Li J, Jiang D (2020) Dispersion and properties of zirconia suspensions for stereolithography. Int J Appl Ceram Technol 17:239-247. https:// doi.org/10.1111/ijac.13321

41. Hassanin H, El-Sayed MA, Elshaer A, Essa K, Jiang K (2018) Microfabrication of net shape zirconia/alumina nanocomposite micro parts. Nanomaterials 8. https://doi.org/10.3390/nano8080593

42. He R, Liu W, Wu Z, An D, Huang M, Wu H, Jiang Q, Ji X, Wu S, Xie Z (2018) Fabrication of complex-shaped zirconia ceramic parts via a DLP- stereolithography-based 3D printing method. Ceram Int 44:3412-3416. https://doi.org/10.1016/j.ceramint.2017.11.135

43. Bianchi G, Gianella S, Ortona A (2017) Design and additive manufacturing of periodic ceramic architectures. J Ceram Sci Technol 8:59-66. https://doi.org/10.4416/JCST2016-00088

44. Essa K, Hassanin H, Attallah MM, Adkins NJ, Musker AJ, Roberts GT, Tenev N, Smith M (2017) Development and testing of an additively manufactured monolithic catalyst bed for HTP thruster applications. Appl Catal A Gen 542:125-135. https://doi.org/10. 1016/j.apcata.2017.05.019

45. Bach C, Dimopoulos Eggenschwiler P (2011) Ceramic foam catalyst substrates for diesel oxidation catalysts: pollutant conversion and operational issues. SAE Tech Pap 20110459. https://doi.org/10. 4271/2011-24-0179

46. Ibrahim HA, Abdou S, Ahmed WH (2017) Understanding flow through catalytic converters. In: Proceedings of the 4th International conference of Fluid Flow, Heat and Mass Transfer (FFHMT'17). Proceedings of the 4th International Conference of Fluid Flow, Heat and Mass Transfer (FFHMT'17), Toronto

47. Amirnordin SH, Seri SM, Salim WS-IW, Rahman HA, Hasnan K (2011) Pressure drop analysis of square and hexagonal cells and its effects on the performance of catalytic converters. Int J Environ Sci Dev 2:239-247

48. Ansys CFX-Solver, Release 16.0: CFX-Solver Manager User's Guide (2015)

49. Lynch CT (1975) CRC handbook of material science, Volume III: nonmetallic materials and applications. CRC Press, Boca Raton

50. Zhao H, Yu F, Bennett TD, Wadley HNG (2006) Morphology and thermal conductivity of yttria-stabilized zirconia coatings. Acta Mater 54:5195-5207. https://doi.org/10.1016/j.actamat.2006.06. 028 
51. Koltsakis GC (1997) Warm-up behavior of monolithic reactors under non-reacting conditions. Chem Eng Sci 52:2891-2899. https:// doi.org/10.1016/S0009-2509(97)00097-3

52. Durat M, Parlak Z, Kapsiz M, Parlak A, Fiçici F (2013) Cfd and experimental analysis on thermal performance of exhaust system of a spark ignition engine. J Therm Sci Technol 33:89-99

53. Fernández-Yáñez P, Armas O, Gómez A, Gil A (2017) Developing computational fluid dynamics (CFD) models to evaluate available energy in exhaust systems of diesel light-duty vehicles. Appl Sci 7. https://doi.org/10.3390/app7060590

54. Lage JL, Lemos MJS De, Nield DA (2002) 8 - Modeling turbulence in porous media. In: Ingham DB, Pop I (eds) Transport Phenomena in Porous Media II. Pergamon, Oxford, pp 198-230

55. Varghese G, Moral M, Castro-García M, López-López JJ, MarínRueda JR, Yagüe-Alcaraz V, Hernández-Afonso L, Ruiz-Morales JC, Canales-Vázquez J (2018) Fabrication and characterisation of ceramics via low-cost DLP 3D printing. Bol la Soc Esp Ceram y Vidr 57:9-18. https://doi.org/10.1016/j.bsecv.2017.09.004

56. Inayat $\mathrm{A}$, Schwerdtfeger $\mathrm{J}$, Freund $\mathrm{H}$, Körner $\mathrm{C}$, Singer RF, Schwieger W (2011) Periodic open-cell foams: pressure drop measurements and modeling of an ideal tetrakaidecahedra packing. Chem Eng Sci 66:2758-2763. https://doi.org/10.1016/j.ces.2011. 03.031

57. Tsinoglou DN, Koltsakis GC, Missirlis DK, Yakinthos KJ (2004) Transient modelling of flow distribution in automotive catalytic converters. Appl Math Model 28:775-794. https://doi.org/10. 1016/j.apm.2003.12.006

58. Dimopoulos Eggenschwiler P, Tsinoglou DN, Seyfert J, Bach C, Vogt U, Gorbar M (2009) Ceramic foam substrates for automotive catalyst applications: fluid mechanic analysis. Exp Fluids 47:209222. https://doi.org/10.1007/s00348-009-0653-2
59. Inayat A, Klumpp M, Lämmermann M, Freund H, Schwieger W (2016) Development of a new pressure drop correlation for opencell foams based completely on theoretical grounds: taking into account strut shape and geometric tortuosity. Chem Eng J 287: 704-719. https://doi.org/10.1016/j.cej.2015.11.050

60. Ekström F, Andersson B (2010) Pressure drop of monolithic catalytic converters experiments and modeling. SAE Tech Pap Ser 1. https://doi.org/10.4271/2002-01-1010

61. Kumar A, Mazumder S (2010) Toward simulation of full-scale monolithic catalytic converters with complex heterogeneous chemistry. Comput Chem Eng 34:135-145. https://doi.org/10.1016/j. compchemeng.2009.05.018

62. Kim JY, Son S (1999) Improving flow efficiency of a catalytic converter using the concept of radially variable cell density. Part I SAE Tech Pap Ser. https://doi.org/10.4271/1999-01-0769

63. Bracconi M, Ambrosetti M, Maestri M, Groppi G, Tronconi E (2018) A fundamental analysis of the influence of the geometrical properties on the effective thermal conductivity of open-cell foams. Chem Eng Process Process Intensif 129:181-189. https://doi.org/ 10.1016/j.cep.2018.04.018

64. Jeong S-J, Kim W-S, Kim T (2005) An application of CFD to improve warm-up performance of the 3-way auto-catalyst by high surface area and low thermal mass. Int J Veh Des 29:243. https:// doi.org/10.1504/ijvd.2002.002012

65. Klumpp M, Körner C, Inayat A, Schwerdtfeger J, Freund H, Schwieger W, Singer RF (2014) Periodic open cellular structures with ideal cubic cell geometry: effect of porosity and cell orientation on pressure drop behavior. Chem Eng J 242:364-378. https:// doi.org/10.1016/j.cej.2013.12.060

Publisher's note Springer Nature remains neutral with regard to jurisdictional claims in published maps and institutional affiliations. 